\title{
Connections of climate change and variability to large and extreme forest fires in southeast Australia
}

\author{
Nerilie J. Abram (1D et al."
}

The 2019/20 Black Summer bushfire disaster in southeast Australia was unprecedented: the extensive area of forest burnt, the radiative power of the fires, and the extraordinary number of fires that developed into extreme pyroconvective events were all unmatched in the historical record. Australia's hottest and driest year on record, 2019, was characterised by exceptionally dry fuel loads that primed the landscape to burn when exposed to dangerous fire weather and ignition. The combination of climate variability and long-term climate trends generated the climate extremes experienced in 2019, and the compounding effects of two or more modes of climate variability in their fire-promoting phases (as occurred in 2019) has historically increased the chances of large forest fires occurring in southeast Australia. Palaeoclimate evidence also demonstrates that fire-promoting phases of tropical Pacific and Indian ocean variability are now unusually frequent compared with natural variability in preindustrial times. Indicators of forest fire danger in southeast Australia have already emerged outside of the range of historical experience, suggesting that projections made more than a decade ago that increases in climate-driven fire risk would be detectable by 2020 , have indeed eventuated. The multiple climate change contributors to fire risk in southeast Australia, as well as the observed non-linear escalation of fire extent and intensity, raise the likelihood that fire events may continue to rapidly intensify in the future. Improving local and national adaptation measures while also pursuing ambitious global climate change mitigation efforts would provide the best strategy for limiting further increases in fire risk in southeast Australia.

$\mathrm{T}$ he bushfires that burnt across southeastern Australia's temperate forests in the 2019/20 fire season were unprecedented in their scale, intensity and impacts. Collectively, this fire season has been termed Australia's Black Summer. The mega forest fires ${ }^{1}$ began in early September 2019 in southeast Queensland, and during the fire season hundreds of fires developed southwards through forests in New South Wales (NSW), the Australian Capital Territory (ACT), Victoria and South Australia (Fig. 1a). Many of these fires remained active and uncontrolled for months, until rainfall in February 2020 eased conditions. More than 23\% of the temperate forests in southeastern Australia were burnt in the 2019/20 fire season (Methods), making the scale of these forest fires unprecedented both in an Australian and global context ${ }^{1-3}$. The radiative power

\footnotetext{
\#A list of authors and their affiliations appears at the end of the paper.
} 

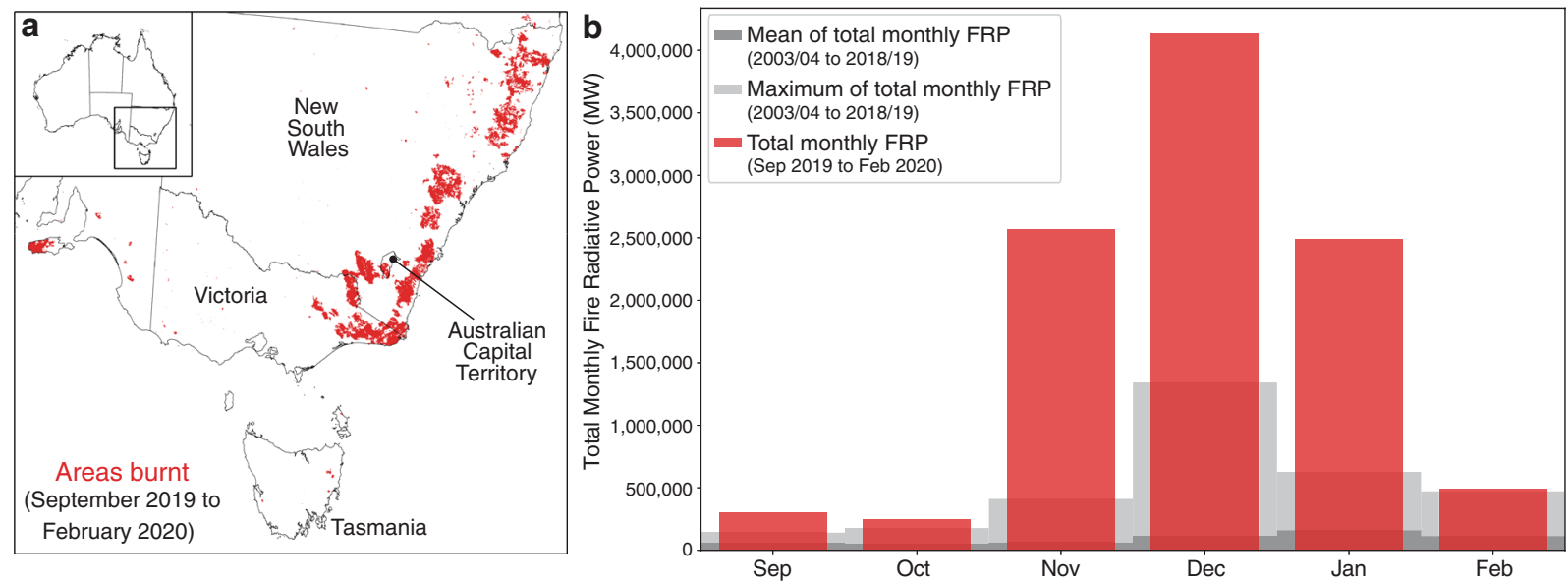

Fig. 1 Area and intensity of the Black Summer fires in southeast Australia. a Map of areas burnt (red) between September 2019 and February 2020 (spring and summer), based on MODIS (Moderate Resolution Imaging Spectroradiometer) data. The term southeast Australia is used in this study to represent the combined states of New South Wales (NSW), Australian Capital Territory (ACT) and Victoria. b Monthly total Fire Radiative Power (FRP) in southeast Australia derived from MODIS observations made from the Terra and Aqua satellites (Methods) 125,126 shown for September 2019 to February 2020 (red), and compared with the monthly mean total FRP (dark grey) and monthly maxima total FRP (light grey) over the same spring and summer interval from September 2003 to February 2019. See also Supplementary Fig. 1 for daily FRP.

from the 2019/20 fires in southeast Australia was the highest on record for every month of the spring and summer fire season (Fig. 1b and Supplementary Fig. 1). The number of fires that developed into violent pyroconvective storms during the 2019/20 fire season was also unprecedented ${ }^{4,5}$.

The Black Summer fires resulted in extensive social, environmental and economic impacts ${ }^{3,6}$. The direct social impacts included the loss of 33 lives and the destruction of over 3000 houses $^{3}$. Indirect health impacts attributed to smoke exposure include an estimated 417 lives lost and 3151 hospitalisations ${ }^{7}$. Longer-term health impacts can be difficult to quantify, but in the years following previous major fire events ongoing post-traumatic stress disorder and depression have been reported among fireaffected populations ${ }^{8}$. Environmental impacts will take some time to become fully apparent, and urgent reassessments of the extinction vulnerability of fire-impacted species are needed ${ }^{6}$. In the state of NSW, where the majority of the fires occurred, up to 293 threatened fauna species and 680 threatened flora species may have been impacted ${ }^{9}$. Importantly, $37 \%$ of the state's rainforests were fire-affected, including $54 \%$ of the Gondwana Rainforests, Australia World Heritage Area ${ }^{9}$. These rainforest communities are not generally considered to be resilient to fire ${ }^{10}$. Even in ecological communities that are resilient to fire, such as resprouting eucalypt forests, the combined impacts of severe drought had already stressed these ecosystems ahead of the Black Summer fires ${ }^{11}$ and recurrent fire damage in some areas may impair the ability of ecosystems to recover ${ }^{12}$. In economic terms, the Black Summer fires are expected to be Australia's costliest natural disaster to date $\mathrm{e}^{13}$.

The 2019/20 fire crisis in Australia generated intense community and political discussion on the role of climate change in forest fire risk. Scientific assessments have concluded that humancaused climate change is expected to increase the risk of fires, including extreme fires, in Australia and other parts of the world ${ }^{14-17}$. Some assessments had projected that the influence of human-caused climate change on increasing fire weather days in southeast Australia should be directly observable by $2020^{18}$, while other studies suggest that indicators of increasing fire risk in this region will only become detectable outside of the range of natural variability much later this century ${ }^{19}$. The range of interacting climate factors that contribute to forest fires in Australia confounds attempts to attribute changing fire risk to any single factor (Box 1 and Box Fig. 1). At the same time, multiple climatic influences raise the possibility that climate change could have a non-linear effect on forest fire risk. In this review, we examine the ways that climate variability and climate change are altering the risk of large and extreme forest fires in southeast Australia, while acknowledging that the ultimate impact of fires on people and ecosystems is also determined by a range of non-climatic factors that fall outside of the scope of this review. Our assessment includes an examination of the confluence of climate factors that resulted in the 2019 climate extremes and the Black Summer mega forest fires.

\section{Climate in southeast Australia}

2019 was Australia's hottest and driest year on record, both nationwide and in southeast Australia (Fig. 2; Methods). Human activities have increased atmospheric carbon dioxide levels by around $50 \%$ relative to pre-industrial levels, and resulted in around $1.0^{\circ} \mathrm{C}$ of global warming ${ }^{20}$. Australia's climate is also warming as part of this unequivocal global warming trend ${ }^{21,22}$. The annual mean temperature in Australia was extreme in 2019; averaged across the whole country the mean temperature was 1.9 ${ }^{\circ} \mathrm{C}$ above the 1911-1940 historical mean, and was $2.0^{\circ} \mathrm{C}$ above this historical reference level in southeast Australia. The 1911-1940 reference interval is the earliest standard climatology possible for the national temperature data set (Methods), and is used here as the closest approximation to pre-industrial conditions in Australia. Numerous extreme heat records were broken in Australia in 2019, including the warmest national average daily temperature ever recorded of $41.9^{\circ} \mathrm{C}$ on 18th December (Methods).

Ongoing climate warming means that droughts in southeast Australia (and elsewhere) are now occurring on a warmer background climate state (Fig. 2a, b; i.e., droughts are getting hotter). Extremely hot and dry conditions in 2019 were preceded by a widespread and sustained drought across most of eastern Australia that began in NSW in June 2017 (Methods). The initiation of this drought in some places included a flash drought ${ }^{23}$; an extreme event characterised by sudden onset and rapid intensification of drought conditions ${ }^{24}$. The indicators used for 


\section{Box 1 | The four forest fire switches}

The evolution of landscape conditions that increase forest fire risk in southeast Australia (Box Fig. 1) involves a range of climate processes. These climate factors affect the four switches ${ }^{56}$ that are all necessary for large forest fires to develop:

Fuel load (biomass): Australia's temperate forests are primarily composed of eucalypts, and are among the most fire-prone forest type in the world ${ }^{1}$. These environments generally have high fuel loads, comprising leaf and bark litter, dead wood and living foliage. Large fires are more likely to develop in continuous expanses of vegetation, provided fuel is sufficiently dry. Because of the typically high fuel load in Australia's temperate forests (except in the aftermath of fires), it is instead fuel dryness that is usually the major preconditioning factor for forest flammability ${ }^{143}$.

Fuel dryness: Dry fuels allow for the development of large, high-intensity fires 2,143 . In Australia, high solar radiation and low relative humidity, combined with the effects of multi-year droughts, allow forest environments to move into highly flammable states ${ }^{143}$ (Box Fig. 1). Rainfall deficits influence fuel dryness over weeks to interannual time-scales, leading to increased fuel availability (i.e., the fraction of fine dead fuels dry enough to burn). Living vegetation also dries in response to declining soil moisture ${ }^{128}$. Drought promotes leaf shedding in eucalypt forests, generating a significant amount of fuel on the ground. If the drought is severe enough it can cause canopy die-off or tree mortality ${ }^{11}$. Canopy die-off results in (i) an increase in the ratio of dead to live fuels, (ii) an increase in surface fine fuel loads (i.e., litter), and (iii) changes to the microclimate of the forest floor with a more open canopy enhancing the amount of solar radiation penetrating into the forest and driving fuel drying ${ }^{144}$. Widespread fuel dryness can cause naturally occurring firebreaks, such as wet gullies, swamps and south-facing slopes to become ineffective ${ }^{1}$. This allows forest fires to rapidly spread across large regions ${ }^{145}$. Ignition: Fires start by anthropogenic or natural ignition of dry fuels. Anthropogenic sources include accidental ignitions (e.g., fallen power lines) and arson, and these ignitions are more likely to be close to populated areas ${ }^{146}$. Lightning strikes can naturally ignite fire, especially in remote and rugged landscapes where detection and management of fires is difficult ${ }^{146,147}$. Critical fire weather patterns (e.g., passage of dry fronts) and fire-induced weather (e.g. pyrocumulonimbus events) may also be associated with an increased risk of new fire ignitions from lightning strikes, accidental humanrelated ignitions and long-distance spotting from existing fires. The 2019/20 megafires in Australia were initiated primarily by natural and accidental ignitions $^{148}$. There are indications of deliberate community misinformation attempting to attribute the Black Summer fires to arson ${ }^{149,150 .}$

Fire weather: Hot, dry and windy weather enable fire to spread rapidly through the landscape. High Forest Fire Danger Index (FFDI; Box 2) values are indicative of dangerous fire weather conditions where fuels burn readily and fire containment is less likely, which is conducive to the development of large fires that travel long distances ${ }^{151}$. The development of large and extreme bushfires in southeast Australia during spring and summer is frequently driven by the passage of cold fronts ${ }^{72}$. The pre-frontal trough often draws strong, dry northwesterly winds from the interior of Australia and gives rise to heatwave conditions across southeast Australia, which exacerbate surface fire weather and fuel dryness. The passage of a cold front over a bushfire also results in a rapid change in wind direction, which transforms the flank of a bushfire into a long and fast-moving fire front that is difficult to control. Frontal weather systems are also associated with increased atmospheric instability, which can enhance the vertical development of bushfire plumes, making fires more likely to couple with the atmosphere and develop into extreme pyroconvective fire events.
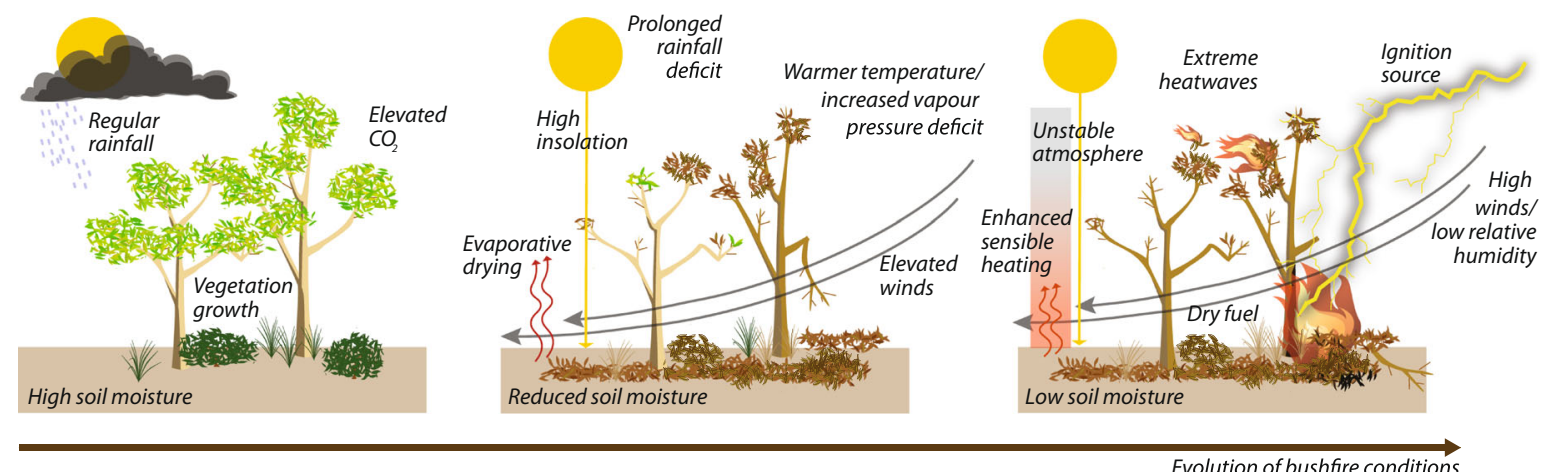

Box Fig. 1 Climate processes associated with forest fire risk.

Schematic of the processes important for forest fires (bushfires) in southeast Australia, and the evolution of landscape conditions conducive for large and extreme forest fires.

monitoring drought in NSW (Methods) show that 12-month soil moisture and plant growth deficits (hydrologic and agronomic drought) developed across large areas of the state, independently of the 12-month rainfall deficits (meteorological drought) that appeared several weeks later. While previous droughts have been linked to decreased rainfall associated with major climate drivers, the current drought started while these modes of variability were in their neutral states. Low rainfall in the autumn of 2018 exacerbated soil water deficits, and by July $2018100 \%$ of the state of NSW was classified as being in meteorologic, hydrologic, or agronomic drought (Methods). Failed winter rainfall seasons in 2018 and again in 2019 resulted in drought intensification in midwinter 2019 and into 2020, driven by low humidity and warm, still days that were interspersed with periods of high wind. Similar to the initial drought onset in 2017, intense drying in 2019 was detected first by the soil water and plant growth indicators followed later by rainfall deficits. Dry conditions also extended into parts of Victoria and southeast Queensland, and the annual mean rainfall for 2019 was the lowest on record when averaged across southeast Australia (Fig. 2b). The fast, widespread initiation of intense agronomic drought sets the 2017-2020 drought apart from some notable previous droughts (Fig. 2b). Above average temperatures have been a constant feature over the 2017-2020 drought. These high temperatures, combined with high surface solar radiation, low surface humidity and high wind, amplified evaporative demand during the initial onset and re-intensification of the drought. There is evidence that the 2017-2020 drought may have led to the most significant amount of tree stress in recent history ${ }^{11}$, with extensive hydraulic failure and canopy dieback observed ${ }^{2}$.

The recent severe drought occurred against a backdrop of longer-term precipitation deficits in southeast Australia over the past 2 decades (Fig. $2 \mathrm{~b}$ ). Of the last 20 years, 15 have seen annual average rainfall below the 1961-1990 climatological mean (Fig. 2b 

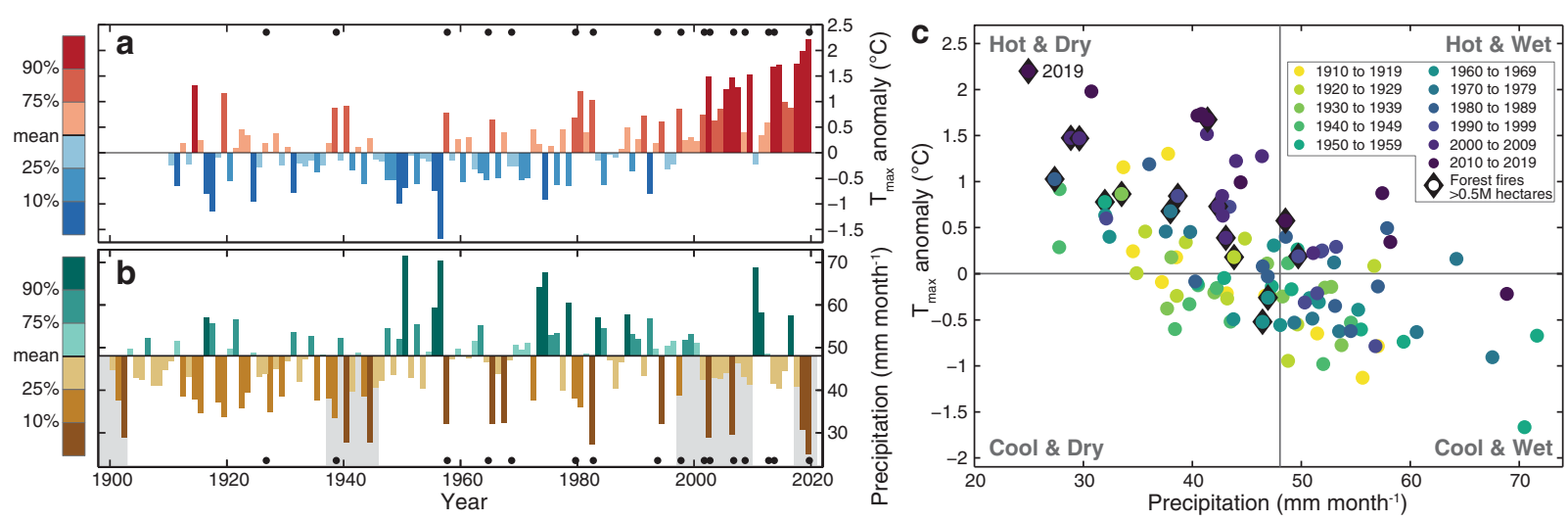

Fig. 2 Temperature, rainfall and large forest fires in southeast Australia. a, b Annual (January-December) means of the daily maximum temperature $\left(T_{\max }\right)$ anomaly (a) and precipitation (b) in the southeast Australian states of NSW, ACT and Victoria (Methods). Horizontal line in (a, b) is the 1961-1990 mean. Black dots in ( $\mathbf{a}, \mathbf{b})$ denote years where forest fires burnt $>0.5 \mathrm{M}$ hectares (Methods). Spring/summer fire seasons are aligned with annual averages of the preconditioning year (i.e., the 2019/20 fire season is shown against 2019 mean climate). Grey shading in b denotes major droughts in southeastern Australia; Federation Drought (1895-1902), WWII drought (1937-1947), Millennium Drought (1997-2009), and the current drought (2017-2020). c Scatterplot of the $T_{\max }$ anomaly, precipitation and large fire data in $(\mathbf{a}, \mathbf{b})$, shaded by decade, and demonstrating the strong linearity of temperature and precipitation in southeast Australia and the preferential occurrence of large fires in hot and dry years. Quadrants in c are defined by the 1961-1990 climatological means.

\section{Box 2 | Indicators for large and extreme forest fires in Australia}

The development of large fires requires ${ }^{56}$ : (i) sufficient fuel load, (ii) fuel that is dry enough to burn, (iii) an ignition source, and (iv) weather that is conducive to carrying fire through the landscape (Box 1). Only if all four conditions are met will major fires take hold ${ }^{117}$. During episodes of critically low fuel moisture content and dangerous fire weather with an unstable lower atmosphere, large fires can escalate further into powerful pyroconvective events that can have disastrous impacts ${ }^{16,17}$. These extreme fires exhibit flaming across large areas (i.e., rather than just along a fire front) and couple with the atmosphere well above the mixed layer, manifesting as towering pyrocumulus (pyroCu) or pyrocumulonimbus (pyroCb) events ${ }^{4}$.

Monitoring for exceedance of critical forest flammability thresholds has the potential to provide an early warning system for catastrophic forest fire risk ${ }^{117}$. Variations in the dryness of dead fuel over short time-scales are often described by indices that vary as a function of temperature and relative humidity, such as the Fuel Moisture Index (FMl; Methods). Transitions to below critical dryness thresholds can occur rapidly, within hours, particularly for the fine dead fuels in the forest litter layer ${ }^{128}$. Dead fuel moisture levels below a critical level of around $10 \%$ have historically been associated with large bushfires in southeast Australia ${ }^{143}$, while fuel moisture levels below $5 \%$ are associated with explosive fire growth with mass generation of embers and spotting 152,153 .

The Forest Fire Danger Index (FFDI) is used operationally in Australia to describe the combined influence of surface meteorological conditions and landscape dryness on bushfire risk in eucalypt forests. The index is calculated using daily maximum temperature, relative humidity, wind speed, and a drought factor ${ }^{43,131}$ (Methods). The drought factor is based on the estimated temporally accumulated soil moisture deficit and antecedent rainfall ${ }^{75}$. Despite known limitations in the FFDI in a warming climate (Methods), high values of the FFDI have continued to be a good indicator of large forest fires in recent years, including the 2019/20 Black Summer.

Extreme pyroconvective fires can develop under conditions with a dry and vertically unstable atmosphere, which is measured in Australia using the continuous Haines index (C-Haines; Methods). Historical occurrences of extreme forest fires have been consistently associated with high levels of $\mathrm{C}$ Haines ${ }^{16,136}$, commonly related to frontal weather systems (Box 1).

and Supplementary Fig. 2), and this is equivalent to the highest number of below average years in any 20 -year interval of the observational record. Notably, the only years in the past 2 decades where annual average rainfall was substantially above average were associated with an extreme La Niña (2010/11) and the strongest negative Indian Ocean Dipole on record ${ }^{25}$ (2016). These phases of large-scale climate variability are important in bringing drought-breaking rain to southeast Australia ${ }^{26,27}$.

There is evidence in recent decades of an emerging signal of sustained declines in cool season rainfall across southern Australia. This is most prominent in southwest Australia, where rainfall is sourced primarily from frontal systems. Winter precipitation in southwest Australia has been below the long-term mean since the 1970s, and the last decade has been the driest on record $^{21,28}$. In southeast Australia, linear rainfall trends calculated since 1900 are non-significant ${ }^{28}$. However, cool season (April-September) rainfall deficits in southeast Australia reached their most extreme level on record in 2019; 18 of the last 20 years have seen below average cool season rainfall, and the accumulated cool season rainfall deficit of the last 20 years $(-939 \mathrm{~mm})$ is the largest since records began (Supplementary Fig. 2; both attributes significant at $p<0.01)$. Declines in cool season rainfall have been connected to intensification of the subtropical high-pressure ridge over southern Australia ${ }^{29}$ and anthropogenically forced positive trends in the Southern Annular Mode ${ }^{30-32}$. These large-scale changes manifest at the synoptic scale as a southward shift in the Southern Hemisphere storm track resulting in fewer low-pressure systems (cyclones) over southern Australia in the cool season ${ }^{33}$. Declines in cool season rainfall across southern Australia in recent decades contrast with increasing warm season rainfall and thunderstorms ${ }^{34}$ over northern Australia.

Strong co-variability exists between maximum temperature and precipitation in southeast Australia due to land-atmosphere feedbacks (Fig. 2c). Consequently, climatic conditions in this region tend to fall upon a linear relationship between wet-andcool or dry-and-hot states $(r=-0.62, p<0.01$ for annual 
averages). Rainfall deficits are generally associated with reduced cloud cover that increases incoming shortwave radiation and contributes to surface temperature increases ${ }^{35}$. High temperatures tend to increase the vapour pressure deficit (VPD), which, together with high radiation and wind speeds, increases evaporative demand and causes drying of the landscape and intensification of droughts $^{36-38}$. Dry landscapes have less capacity for evaporative cooling through the transfer of energy into latent heat ${ }^{35}$, leading to increased sensible heat fluxes that further amplify warm air temperatures through the boundary layer ${ }^{39}$. Dry conditions in southeast Australia also reduce the precipitation derived from the recycling of water within the landscape, further intensifying dry and hot conditions ${ }^{40}$. In years of dry-and-hot conditions in southeast Australia there is elevated fire potential through these combined climatic effects on fuel dryness and fire weather (Box 1). Historical evidence demonstrates this effect; large forest fires in southeast Australia (where $>0.5$ million hectares of forest was burnt) all cluster in or near the dry-and-hot quadrant of historical climate conditions (Fig. 2c).

\section{Climate variability that contributes to fire risk}

The extreme conditions experienced in southeast Australia in 2019 (Fig. 2) reflect the combined effects of anthropogenically forced climate trends and natural climate variability. This variability influences the preconditioning of the landscape into a dry state susceptible to burning, as well as the occurrence of extreme fire weather during the fire season (Box 1). The fire season typically runs from spring to autumn in southeast Australia ${ }^{41}$, and the multiple drivers of climate variability that influence climate extremes before and during the fire season include the $\mathrm{El}$ Niño-Southern Oscillation (ENSO), Indian Ocean Dipole (IOD) and the Southern Annular Mode (SAM) (Fig. 3) ${ }^{42}$.

ENSO is the main driver of interannual variability in Australian fire weather as measured by the Forest Fire Danger Index (FFDI; Box 2, Methods) ${ }^{42}$. El Niño events are associated with hot and dry conditions across eastern Australia, resulting in more frequent dangerous FFDI days during the build-up and peak of El Niño in spring and summer (Fig. 3a, b). Investigations of the impact of ENSO on fire risk in Australia have typically used the Niño3.4 index ${ }^{42,43}$, but sea surface temperature (SST) anomalies in the more western Niño4 region actually have a slightly stronger correlation to precipitation and FFDI variability in southeast Australia (Precipitation: $r_{\mathrm{Niño4}}=-0.63, r_{\mathrm{Niño3.4}}=-0.59$. FFDI: $r_{\text {Niño } 4}=0.61, \quad r_{\text {Niño3.4 }}=0.56$. Correlations for detrended July-March means, and all are significant at $p<0.01$ ). The Niño4 region is indicative of central-Pacific-type El Niño events. Enhanced atmospheric convection over warm SST anomalies in the Niño4 region promotes atmospheric subsidence over eastern Australia, and these Niño4 anomalies may be sustained over multiple seasons or even years, leading to prolonged climate impacts ${ }^{44}$. Even though ENSO is recognised as the leading driver of interannual variations in fire risk in Australia, it is notable that ENSO was neutral in 2019/20, as classified by the Australian Bureau of Meteorology.

Instead, variability of the IOD and SAM were important in the extremely dry and hot conditions that elevated fire risk in southeast Australia during 2019. One of the most extreme positive IOD events on record occurred in the second half of $2019^{45}$. During positive IOD events cool sea surface temperature anomalies develop in the equatorial southeastern Indian Ocean ${ }^{46,47}$. This suppresses the atmospheric moisture that is normally derived from this region and subsequently drawn across continental Australia ahead of mid-latitude cold fronts. As a result, positive IOD events have historically been associated with droughts and major forest fires in Victoria ${ }^{26,48}$. Climate and
FFDI correlations with the IOD are strongest in spring and have their greatest influence across Victoria and southern NSW ${ }^{42}$ (Fig. 3a, b).

Climate extremes in southeast Australia during the spring and summer of 2019/20 were also influenced by a prolonged negative SAM state. The SAM describes the difference in atmospheric pressure between the mid-latitudes $\left(40^{\circ} \mathrm{S}\right)$ and Antarctica $\left(65^{\circ} \mathrm{S}\right)$ that alters the position and strength of the Southern Ocean westerly storm track. The SAM is highly variable on short timescales (weeks to months), and its impacts on Australian climate differ by season. Driven by anthropogenic changes in greenhouse gas concentrations and stratospheric ozone $e^{49,50}$, the SAM has become more positive over recent decades. This has contributed to reduced cool season (April-September) rainfall over southern Australia. A positive SAM in the warm season (October-March) has a different climatic impact, and is instead associated with cool and wet conditions with low FFDI in most of southeast Australia, and particularly in northeast NSW and southeast Queensland ${ }^{42}$ (Fig. 3a, b). However, in the spring of 2019 a rare sudden stratospheric warming event developed over Antarctica and resulted in a sustained and extreme negative SAM. Negative SAM events associated with sudden stratospheric warming increase the spring and summer fire risk in eastern Australia by reducing cloud cover and contributing to hot and dry conditions across the eastern states $^{51}$.

The drivers of interannual climate variability over southeast Australia do not operate independently of each other, and this increases the chance of compounding effects on fire risk (Fig. 3c). A tight coupling exists across the tropical Indo-Pacific ${ }^{52,53}$, such that fire-promoting positive phases of ENSO and the IOD tend to co-occur. This exacerbates their impacts on fire risk in southeast Australia $^{42}$. Significant interaction also exists between ENSO and SAM, whereby positive ENSO phases tend to be associated with negative SAM state ${ }^{54,55}$. Again, this preferred co-occurrence acts to intensify fire risk in southeast Australia during El Niño/-SAM compound event years. Historically, the compound events associated with co-occurrence of fire-promoting phases (+ENSO, + IOD, and/or -SAM) significantly increase the chance of having large forest fires in southeast Australia (Fig. 3c). Years where large areas $(>0.5 \mathrm{M} \mathrm{ha})$ of forest burnt in southeast Australia have most commonly involved one or two of these three drivers cooccurring in their active fire-promoting phases (Fig. 3c; Methods). The co-occurrence of two fire-promoting phases in years of large fires has occurred significantly $(p<0.05)$ more often than would be expected by chance. Likewise, it has historically been significantly $(p<0.05)$ more likely to have no substantial forest area burnt in the years where none of the drivers of climate variability in southeast Australia have been in their firepromoting phases.

The role of climate variability altering the likelihood of large fires in southeast Australia provides some predictability of risk at lead times of a few months prior to the main summer fire season. During 2019, the compound effects on fire potential involved a strong positive IOD event that coincided with a negative SAM. The only other co-occurrence of +IOD and -SAM since 1957 was during the 1982/83 fire season that included the high impact Ash Wednesday fires and which also co-occurred with +ENSO (i.e., all three modes were in their fire-promoting phases). The unusual $+\mathrm{IOD} /-$ SAM combination experienced in 2019 increased the area of extreme fire risk, with the -SAM historically having a strong influence on northern NSW and the effect of the +IOD greatest over southern NSW and Victoria (Fig. 3b). This particular combination of interannual variability may have also exacerbated the impacts expected individually from these climate modes; frontal activity associated with the -SAM and more equatorward position 
a. Seasonal influence of climate modes

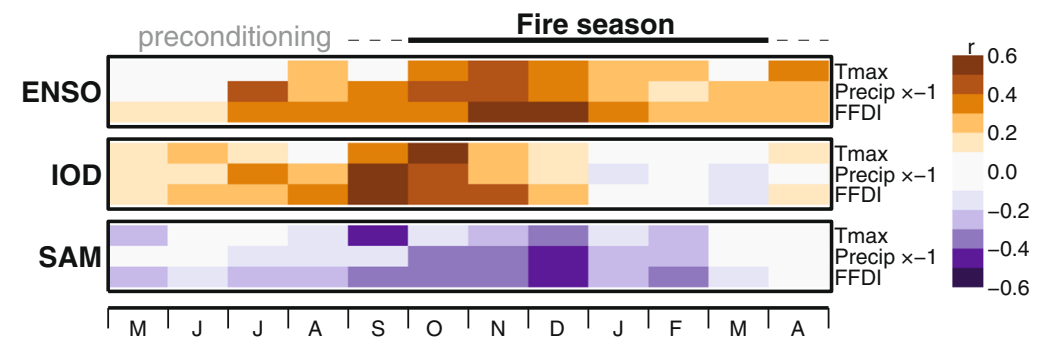

\section{b. Spatial influence of climate modes}
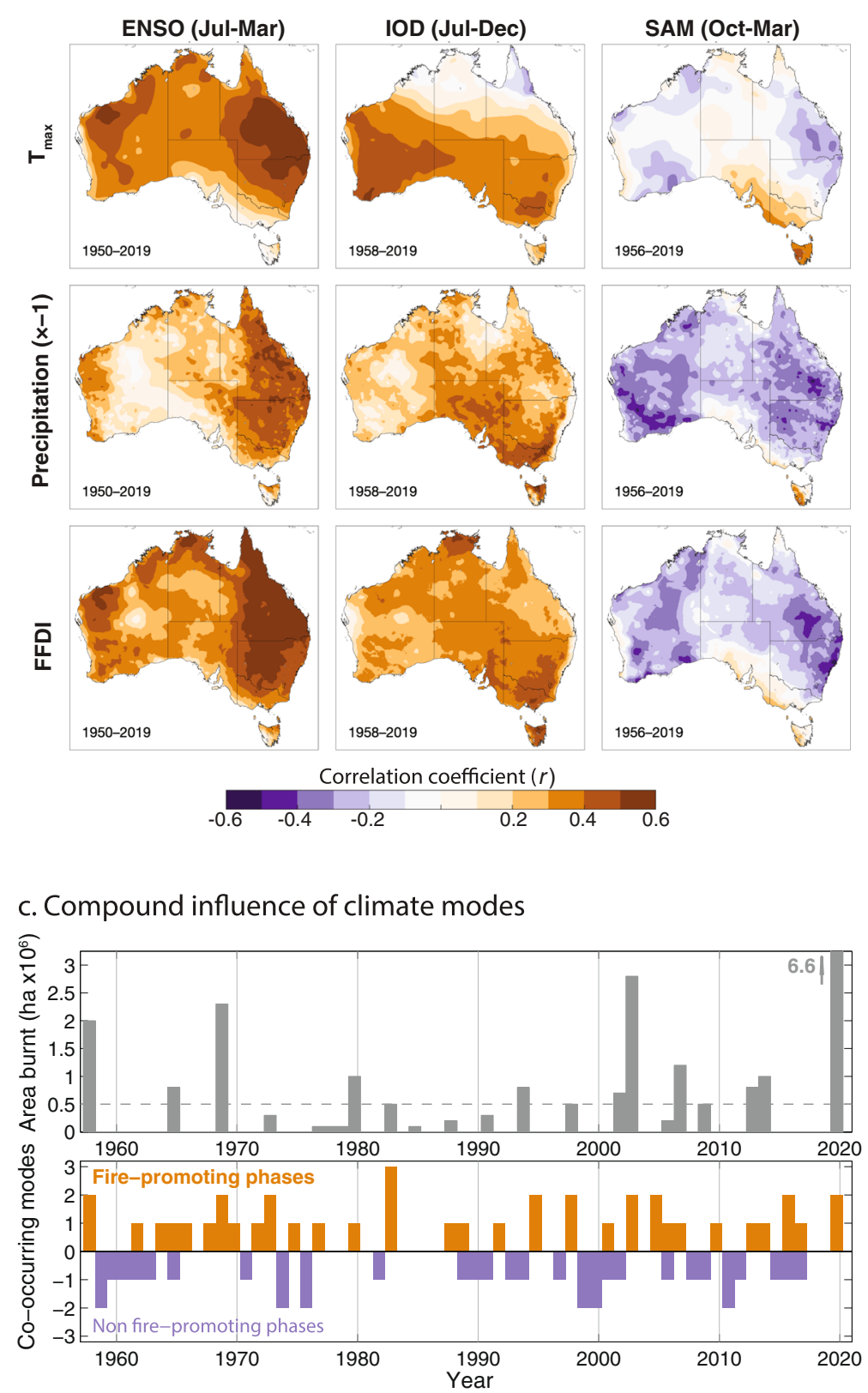

of the Southern Ocean storm track (westerly winds) in 2019 frequently drew air from across the interior of Australia towards the east coast, and the coinciding cool sea surface temperature anomalies in the eastern Indian Ocean meant that this air was unusually dry and hot. The development of this +IOD event was evident in seasonal forecasts from as early as May 2019, and from September the -SAM also formed part of the seasonal climate advice from Australia's Bureau of Meteorology (Methods). 
Fig. 3 Climate variability that influences forest fire risk in southeast Australia. a Seasonality of climate influence of the Niño4 Index (1950-2020), Dipole Mode Index (1958-2020) and SAM Index (1957-2020) with monthly average maximum temperature ( $T_{\max }$ ), precipitation (multiplied by -1) and Forest Fire Danger Index (FFDI) averaged over southeast Australia (Methods). Correlations indicate that high temperature, low rainfall and high FFDI in southeast Australia are associated with +ENSO (EI Niño), +IOD and/or -SAM phases. b Spatial correlation maps of Niño4 index (July-March), Dipole Mode Index (July-December) and SAM Index (warm season; October-March). All correlation analyses (a, b) were carried out on detrended data. c Compound influence of climate modes on large forest fires (>0.5 M hectares) in southeast Australia, showing the number of modes each year in the phase that promotes fire potential $(+E N S O,+I O D,-S A M)$, or in the phase that reduces fire potential $(-E N S O,-I O D,+S A M)$. Active phase determined using the mean over the same active months as used in $\mathbf{b}$, where mean exceeds $\pm 1 \sigma$ for Niño 4 or the Dipole Mode Index, or $\pm 0.5 \sigma$ for the SAM index based on detrended data normalised to 1961-1990 (Methods). Monte Carlo testing of the compound influence of climate modes on the historical occurrence of large ( $>0.5 \mathrm{M}$ hectares) fires indicates that having none of the modes of variability in their fire-promoting phase significantly reduces the chance of having a large fire season in southeast Australia, relative to a random process $(p<0.05)$. The co-occurrence of two modes in their fire-promoting phases, as occurred in 2019, significantly increases the chances of experiencing a large fire season in southeast Australia, relative to what would be expected by chance $(p<0.05)$ (Methods).

\section{Palaeoclimate perspectives}

Australia is the most fire-prone continent on Earth ${ }^{4,56}$, and the accumulation of charcoal in Australia is now higher than at any other time during the last 70,000 years ${ }^{57}$. Since the Industrial Revolution fire activity globally has transitioned from being primarily climate driven into an anthropogenic regime, where fire occurrence and spread is also influenced by land clearing and landscape management, and by the direct human influence on fire ignition and suppression ${ }^{58,59}$. In Australia, there has also been a disruption of Indigenous land management practices ${ }^{57,60}$, which included high-frequency, low-intensity burning in some areas. Historical accounts and palaeoclimate evidence document areas of native grassland maintained by Indigenous management that in some cases have transitioned into temperate forest landscapes since European colonisation 60 .

Palaeoclimate evidence demonstrates that climate variability across a range of time-scales altered Australia's fire activity in the past. Temperature was quantitatively the most important driver of changes in biomass burning globally over at least the past 21,000 years $^{61}$. Fire regimes in Australia also predominantly followed global temperature changes on glacial-interglacial timescales, with colder periods resulting in less vegetation productivity, less available fuel and less burning ${ }^{57}$. The spatial patterns of Holocene fire history in southeast Australia show a latitudinally varying response on millennial time-scales ${ }^{57}$. Decreased fire activity in Tasmania and southern Victoria tended to coincide with increased fire activity in eastern NSW, and vice versa. This structure is consistent with the latitudinal reversal in the impact that the SAM causes on climate anomalies and fire risk in southeast Australia (Fig. 3b). In Tasmania, centennial-scale fluctuations in the SAM have also been shown to be associated with pollen-indicators of drought stress in vegetation and fluctuations in fire activity during the last two millennia ${ }^{62}$. Many studies have also looked at potential correlations between an increase in ENSO variability since the mid Holocene and changes in Australian and Southern Hemisphere charcoal accumulation, but no clear signal has so far been found ${ }^{57,63}$. It is possible that this is due to the confounding influence of changes in the SAM, that would have reduced the spatial coherence of any fire regime changes caused by ENSO. Assessment of any influence of Holocene changes in the IOD have not yet been possible due to the lack of reconstructions of IOD variability over this time scale.

Human-caused climate change is now altering the behaviour of the drivers of interannual climate variability in southeast Australia. In some instances, these changes have increased the occurrence of fire-promoting phases above the range of natural variability experienced in recent centuries to millennia (Fig. 4). A significant $(p<0.01)$ increase in ENSO variability has seen SST variability in the Niño3.4 region over the past 50 years become approximately $25 \%$ stronger than in pre-industrial times ${ }^{64}$. Changes in ENSO have also involved central-Pacific-type El Niño events becoming more frequent than any other time over at least the past 400 years $^{65}$ (Fig. 4). Positive IOD events are also occurring more frequently now than at any reconstructed time of the last millennium (Fig. 4), and the increase in positive IOD frequency has also been accompanied by a transition to a more positive IOD-like mean state in Indian Ocean climate ${ }^{45,53}$. Stratospheric ozone depletion and rising greenhouse gas concentrations ${ }^{49,50}$ have caused the mean summer SAM to become more positive since the mid-twentieth century than at any time in last millennium ${ }^{66}$, moving this driver away from its fire-promoting phase during the warm season in southeast Australia (Fig. 4). However, the success of the Montreal Protocol has resulted in stabilisation of Antarctic ozone depletion and caused the summer SAM trend to pause in the past two decades ${ }^{67,68}$. The palaeoclimate perspective across these three drivers of climate variability demonstrates that the likelihood of fire-promoting climate variability impacting southeast Australia has become unusually high in recent decades, specifically in relation to variability originating from the tropical oceans (Fig. 4).

\section{Observed changes in Australia's fire season}

Extreme climate conditions in southeast Australia resulted in December 2019 having the most dangerous fire weather since records of the FFDI began in 1950 (Fig. 5a-c and Box 2, Methods). December 2019 also had the driest fuel load on record in southeast Australia, as indicated by the Fuel Moisture Index (FMI) (Fig. 5d-f and Box 2, Methods). The fire risk in southeast Australia between September 2019 and February 2020 was characterised by spatially extensive and temporally unrelenting high background levels of fuel dryness and fire weather ${ }^{1}$, upon which episodes of critical (and record breaking) fire weather and fuel drying occurred. Satellite observations of fire radiative power in spring and summer since 2003 confirm that FFDI and FMI have been reliable indicators of resulting fire intensity in southeast Australia, with linear increases (decreases) in FFDI (FMI) associated with exponential intensification of the radiant energy released from burning vegetation (Fig. $5 c$, f). The total radiative power from fires burning in southeast Australia was the highest on record for every month of the spring and summer of 2019/20 (Fig. 1b, Supplementary Fig. 1). The record-breaking fire risk recorded by the FFDI and FMI during the 2019/20 fire season was also matched by record-breaking fires in terms of both the area burnt and the number of fires that developed into extreme pyroCb events (Supplementary Fig. 3).

A clear trend towards more dangerous weather conditions for forest fires in Australia has been observed since the mid-twentieth century ${ }^{42,43}$. Increasingly dangerous weather conditions are observed for both the mean FFDI and extreme (90th percentile) FFDI, with the most significant trends occurring in southeast Australia and being most pronounced in the spring ${ }^{43}$. Positive 


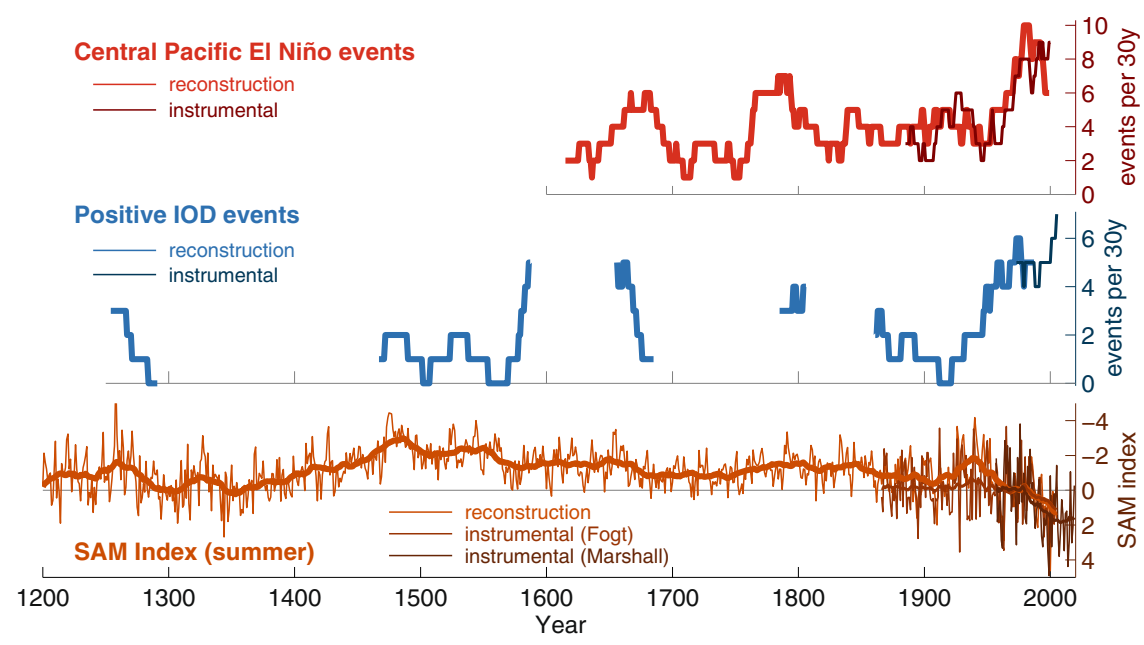

Fig. 4 Changes in modes of climate variability during the last millennium. Palaeoclimate reconstructions and instrumental data are shown for centralPacific El Niño event numbers ${ }^{65}$, positive IOD event numbers ${ }^{53}$, and the summer SAM Index relative to the 1961-1990 mean ${ }^{66}$ (thin lines are annual summer SAM values; thick lines are 30-year running means). Note inverted y-axis for SAM Index so that the upward direction for each plot is toward more fire-promoting conditions in southeast Australia (Fig. 3). The increasing frequency of central-Pacific-type El Niño events and of positive IOD events in recent decades mean that these fire-promoting phases are now occurring more often than any other time in the last several centuries. Positive trends in the summer SAM in the twentieth century have moved this mode away from its fire-promoting phase, but this trend has paused in the past two decades due to ozone recovery ${ }^{68}$.
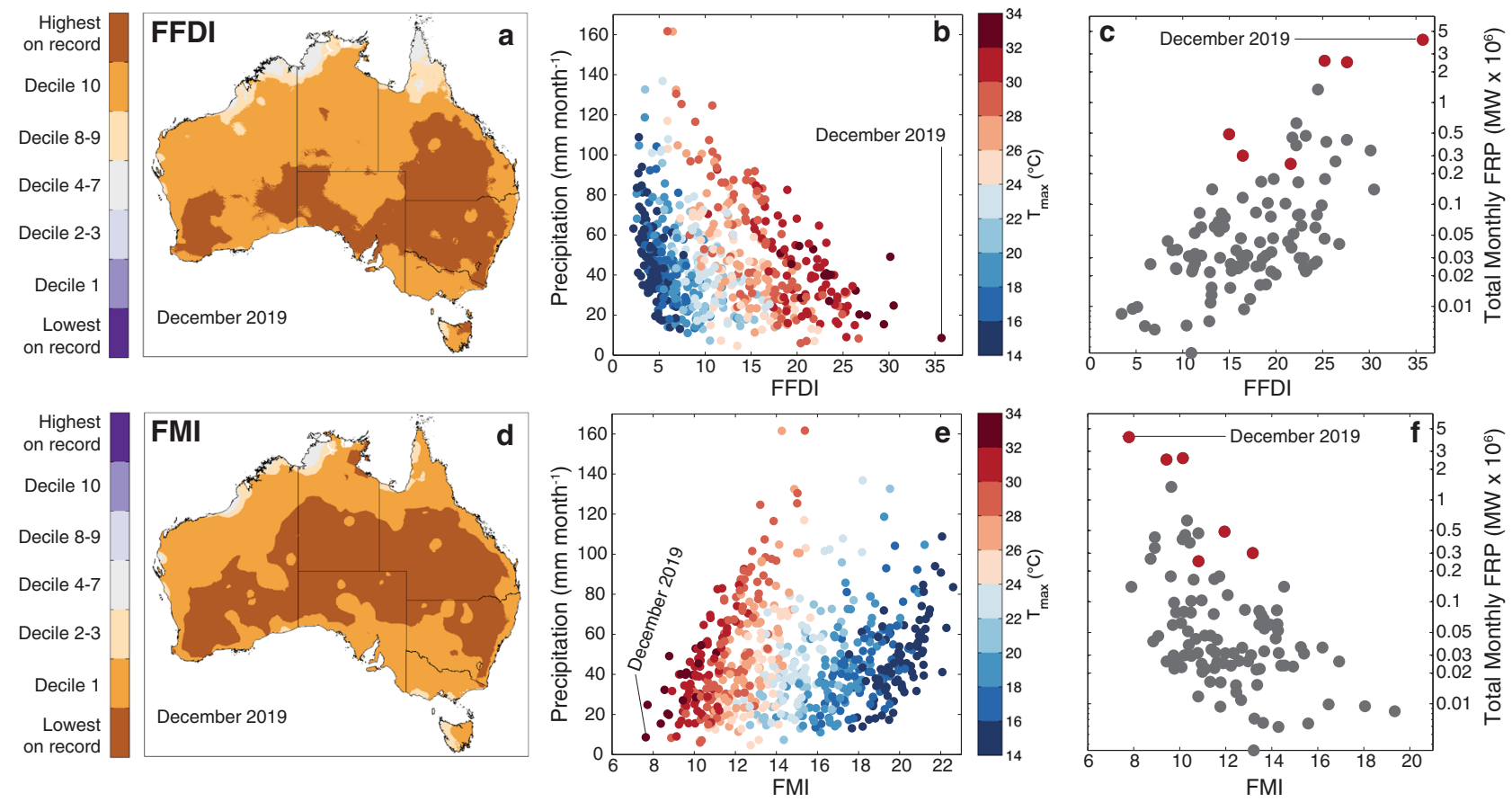

Fig. 5 Fire risk indices and fire history in southeast Australia. a Spatial deciles of FFDI in December 2019. b Scatterplot of monthly mean FFDI (January 1970 to February 2020) averaged over southeast Australia shown relative to monthly mean precipitation ( $y$-axis) and $T_{\max }$ (colours). December 2019 values were the most extreme on record across large parts of southeast Australia (a), and in regional mean (b). c Mean monthly FFDI across southeast Australia in spring and summer months (September to February) compared with observed monthly total fire radiative power (FRP) in southeast Australia. FRP data from September 2003 to February 2020 (Methods). Data for the 2019/20 Black Summer are shown in red. Note logarithmic scale on FRP axis. d-f, as in a-c but for FMI data spanning January 1970 to December 2019. See also Supplementary Fig. 3 for comparison of FFDI and FMI with the history of burnt area and pyroCb event numbers.

trends in the FFDI are resulting in increasingly severe fire weather in the summer, as well as lengthening of the fire season with an earlier start to the fire season now compared to the mid-twentieth century. There is also recent evidence indicating a trend in coastal southeast Australia for more frequent dry lightning events since 1979 , a key natural source of wildfire ignition ${ }^{34}$. Formal attribution of observed trends in dangerous fire weather in southeast Australia to anthropogenic climate change has not been done. However, the trends in FFDI are partly caused by rising temperatures (Methods) ${ }^{43}$, and rising temperatures in Australia have been robustly attributed to human causes $^{69}$. The increase in dangerous fire weather ${ }^{43}$ has been accompanied by an 
observed decrease in the return time between major fire events ${ }^{4}$ (Fig. 2a, b).

There has been a marked increase in the number of forest fires that are now developing into extreme pyroconvective (pyroCb) events. These events can have catastrophic consequences for people and the environment, as seen through the losses associated with the 2003 Canberra and 2009 Black Saturday pyroconvective fire events. Since satellite records began, and prior to 2019, there had been a total of 60 confirmed or suspected pyroCb events in southeast Australia ${ }^{4,70}$ (Sharples, unpublished data; Supplementary Fig. 3). During the 2019/20 Black Summer it is estimated that an unprecedented 29 additional pyroCb fire events occurred (Supplementary Fig. 3). This included at least 18 pyroCb events over a single week that had previously undocumented impacts on winds and chemical composition into the stratosphere ${ }^{5}$, and a planetary-scale radiative forcing effect equivalent to a moderate volcanic eruption ${ }^{71}$. The extraordinary number of extreme fire events demonstrate the historical and global significance of the Black Summer fire season in southeast Australia. The critical fire weather conditions associated with pyroconvection frequently include the passage of strong fronts across southeast Australia ${ }^{72}$, and include the interaction of these fronts with mountainous terrain to produce foehn-like winds ${ }^{16,73}$. An increase in potential for pyroconvection, as measured by the C-Haines index (Box 1, Methods), has been observed in southeast Australia due to decreased vertical atmospheric stability and increased dryness of the lower troposphere ${ }^{74}$. Increases in pyroconvection risk (CHaines) during spring and summer also coincide with increases in dangerous surface weather (FFDI) in southeast Australia ${ }^{74}$. This has increased the frequency of compound events, where the combined influence of dangerous surface weather conditions with changes in tropospheric stability and humidity have escalated the risk of large and extreme fires in some parts of southeast Australia ${ }^{16,17,74}$.

There is evidence that dangerous fire weather in southeast Australia has emerged outside of the range of historical experience (Fig. 6 and Supplementary Fig. 4; Methods). Using the observed mean annual FFDI between 1950-1999 as the 50-year historical reference interval, the signal of the 30-year lowess filtered FFDI in southeast Australia has emerged above the $+2 \sigma$ natural variability level since 2015, and in 2019 the mean FFDI was at $+4.5 \sigma$ relative to the historical mean (Fig. 6a, b). Seasonally, the signal of emergence in the FFDI has been strongest (exceeding $+2 \sigma$ threshold) in spring and summer (Supplementary Fig. 4). Emergence of the FFDI outside of the range of historical experience is not only related to rising temperature, but is also seen in fire danger indicators of long-term and short-term drying (Fig. 6c-f). The Keetch-Byram Drought Index (KBDI; Methods $)^{75}$ is an indicator of soil moisture deficit and shows emergence of the signal in southeast Australia above the $+1 \sigma$ level since 2011 and highest mean annual values on record in 2019 (Fig. 6c, d). An alternate index of drought based on water
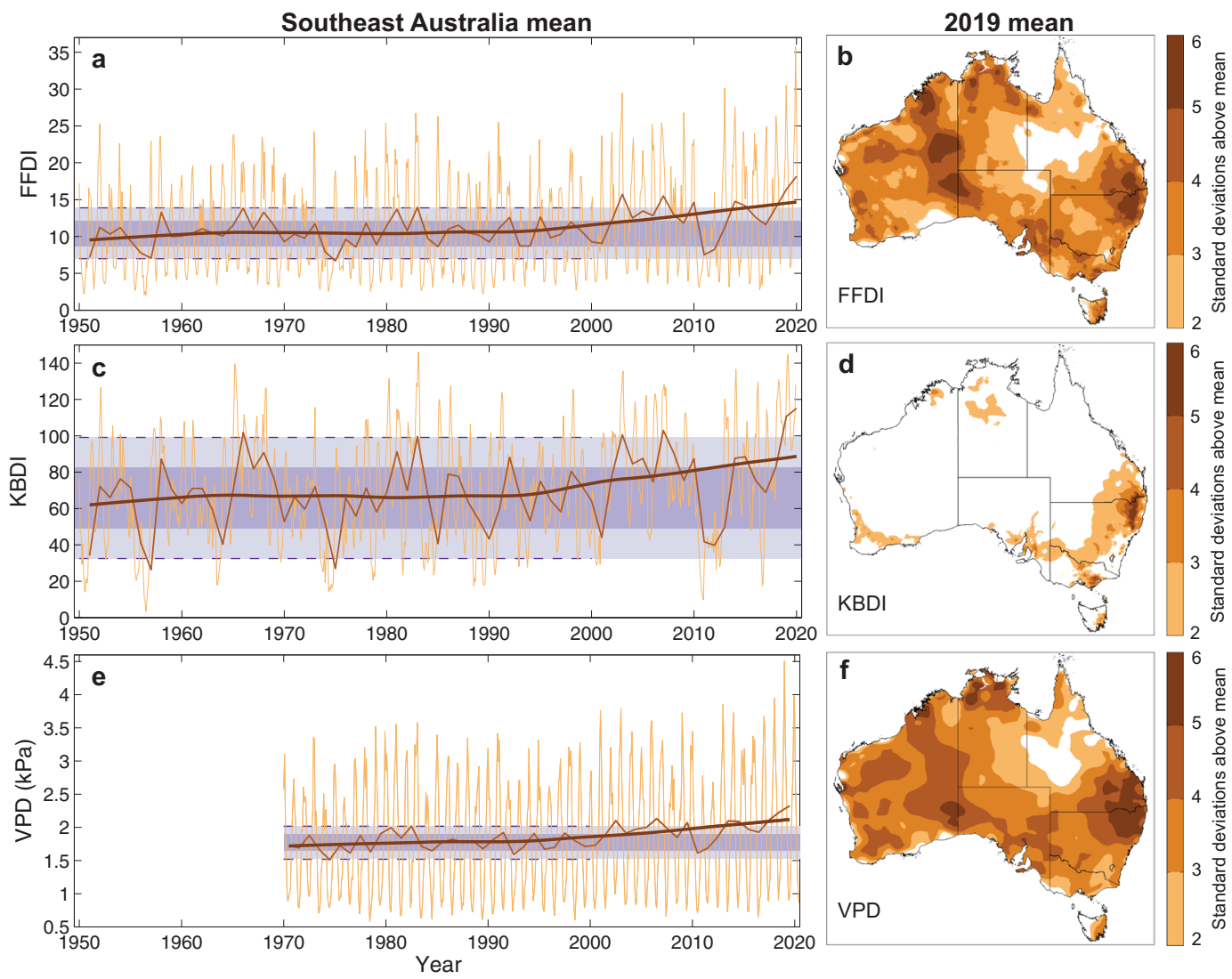

Fig. 6 Emergence of changes outside of historical experience in observed fire potential indicators. a Time series of mean monthly (light brown) and annual (mid brown) FFDI in southeast Australia, and the long-term signal as a 30-year lowess filter of annual means (dark brown). Variability of annual FFDI values in the 1950-1999 historical reference interval (dashed lines) is used to define the $\pm 1 \sigma$ (dark purple shading) and $\pm 2 \sigma$ (light purple shading) noise level around the historical mean (Methods). b Spatial plot of the level of the mean FFDI in 2019, expressed as standard deviation level above the historical reference. Values not exceeding the $+2 \sigma$ level of historical variability are masked out. $\mathbf{c}$, $\mathbf{d}$, as in $\mathbf{a}$, $\mathbf{b}$, but for the Keetch-Byram Drought Index (KBDI). e, f, as in $\mathbf{a}, \mathbf{b}$, but for VPD and with a 30-year historical reference period from 1970-1999. See also Supplementary Fig. 4 for the seasonal analysis of FFDI emergence. 
balance, the Standardised Precipitation Evapotranspiration Index $(\mathrm{SPEI})^{76}$, also has emergence in southeast Australia below the $-1 \sigma$ level since 2003 and lowest mean annual values on record in 2019 (not shown). Furthermore, short-term influences on dead fuel moisture as indicated by VPD (Methods) also display emergence above the $+2 \sigma$ level of historical variability since 2012 and highest mean annual values on record in 2019 (Fig. 6e, f). There is considerable interannual variability in these fire risk indicators and so recent changes may not yet represent a permanent state of emergence. However, recent emergence is an indication that a directly observable shift in dangerous fire weather in southeast Australia that is beyond historical experience is underway. This emergence is consistent with projections made more than a decade ago, which suggested that anthropogenic climate change would cause increases in the mean and extreme FFDI in southeast Australia which would be apparent by 2020, and become more pronounced by 2050 especially in a high greenhouse gas emission future ${ }^{77}$.

\section{Future climate-driven changes in fire risk}

Australia's unprecedented Black Summer may be evidence that the intensification of forest fires in southeast Australia as an expected consequence of human-caused climate change has now become observable ${ }^{15,18,78,79}$. The relationship between fire and climate is complex because it involves multiple, interacting processes $^{80}$, and the occurrence of large and extreme fires depends on alignment of climatic and non-climatic conditions (Box 1). Global fire-vegetation models have the potential in the future to allow for assessments of changing fire risk within the complexity of the Earth system, however, these models are currently limited in their ability to simulate the size of historical fires, the length of the fire season and interannual variations in burnt area ${ }^{81}$. Of the currently available fire simulations for historical and future times, none are able to produce fire seasons of the scale seen in southeast Australia in 2019/2082. Because of these fire modelling limitations, we instead focus on the evidence for future climate changes in southeast Australia that contribute to fire risk (Fig. 7).

Continued increases in atmospheric carbon dioxide $\left(\mathrm{CO}_{2}\right)$ levels are unavoidable in the coming decades, and beyond the mid-twenty-first century strongly depend upon collective socioeconomic choices ${ }^{83}$. While there is very high confidence in continuing increases in atmospheric $\mathrm{CO}_{2}$, the vegetation response to these changes and how this may influence fuel load for forest fires is uncertain. Enhanced atmospheric $\mathrm{CO}_{2}$ has the potential to increase plant photosynthesis and consequently fuel loads ${ }^{84}$, but other factors such as climate, water availability and nutrients also determine plant growth. Increased $\mathrm{CO}_{2}$ may reduce water limitation on plant growth in Australia due to increased water use efficiency ${ }^{85}$. However, $\mathrm{CO}_{2}$ enrichment experiments in mature eucalypt forests do not increase aboveground growth and carbon sequestration ${ }^{86,87}$, while tree ring analysis points towards increased water use efficiency without increased tree growth as the historical response of tropical forests to rising atmospheric $\mathrm{CO}_{2}{ }^{88}$. Increasing atmospheric VPD also has the potential to reduce global vegetation growth, offsetting any positive effects from increasing $\mathrm{CO}_{2}{ }^{89}$ and exacerbating drought impacts on vegetation ${ }^{90}$. Overall, there is no clear evidence of whether fuel load in southeast Australia's temperate forests will change markedly as a result of rising atmospheric $\mathrm{CO}_{2}$ levels (Fig. 7).
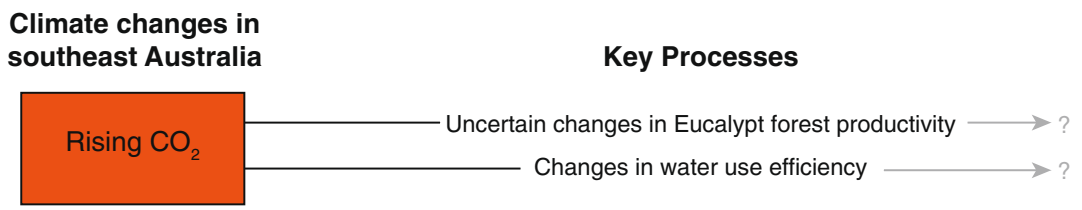

\section{Forest fire} switches

Fuel load
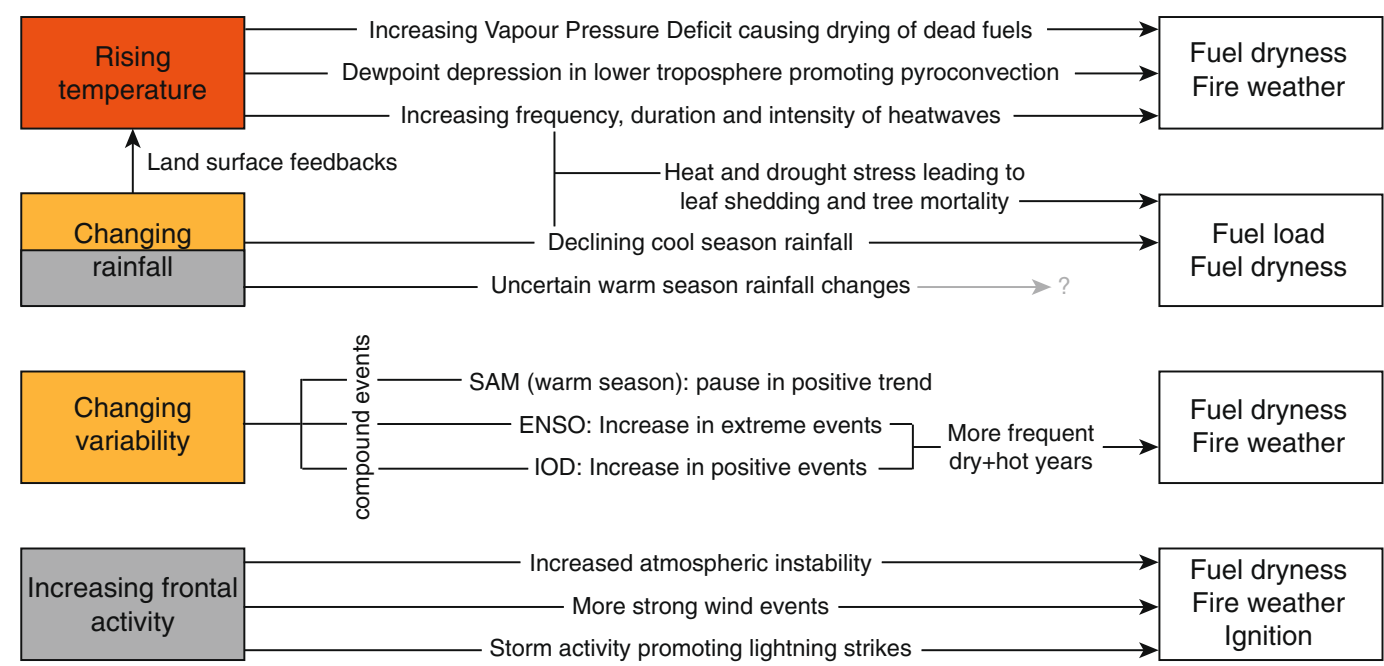

High Confidence / Virtually Certain

Medium Confidence

Low Confidence

Fig. 7 Summary of future anthropogenic climate changes that are expected to alter forest fire risk in southeast Australia. Climate changes are rated as high confidence where the future outcome is virtually certain, rated as medium confidence where multiple lines of evidence support the outcome, and rated as low confidence where multi-model ensembles do not agree on future trends or where climate models are unable to replicate the relevant physical processes. The most common connections between climate changes and fire risk are through changes in fuel dryness and fire weather. 
It is virtually certain that temperatures will rise further this century. Warming in Australia by the end of the century under a low greenhouse gas emission pathway with a socioeconomic focus on sustainability (SSP1-RCP2.6 pathway) may be limited to within $1.5^{\circ} \mathrm{C}-2.7^{\circ} \mathrm{C}$ above pre-industrial ${ }^{91}$. Under the socioeconomic pathway characterised by fossil-fuelled development and high greenhouse gas emissions (SSP5-RCP8.5) mean warming over Australia may be as much as $7^{\circ} \mathrm{C}$ above pre-industrial levels before the end of this century ${ }^{91}$. The intensity, frequency and duration of heatwave extremes are also projected to increase in the future ${ }^{92}$. These future trends in mean and extreme temperatures are expected to increase the occurrence of dangerous fire weather events (Fig. 7). The effect of rising temperature on VPD is also expected to aid the drying of fuels below the critical moisture thresholds needed for large and extreme forest fires, in the absence of counteracting rainfall increases, reduced wind, or decreases in solar radiation (Box 1 and Fig. 7). It has been suggested that warming-driven fuel drying provides the strongest connection of human-caused climate change to the observed increase in Californian wildfires ${ }^{38}$. Precipitation has been a strong modulator of fire extent during the past millennium and historical periods, but some studies point towards an increasing influence of temperature on global fire this century ${ }^{19,59,82}$. Fireenabled modelling indicates that regional warming of around $4{ }^{\circ} \mathrm{C}$ or more above pre-industrial is sufficient to allow megafires to occur in southeast Australia without the need for co-occurring low rainfall ${ }^{82}$. Together, the evidence suggests that in the absence of ambitious global greenhouse gas emission reductions, rapidly rising temperatures will increase forest fire risk in southeast Australia, particularly through the drying of fuels and more dangerous fire weather.

Rainfall changes in Australia have important regional and seasonal patterns, and future precipitation changes remain uncertain in many regions. Precipitation changes in summer and autumn by the end of this century show no consensus across the most recent intercomparison of coupled climate models for any region in Australia ${ }^{91}$. The spread of model results indicate a range of possibilities for southeast Australia from moderate increases to moderate decreases in summer and autumn rainfall, with the central estimate indicating little change ${ }^{91}$. Model agreement in winter and spring has improved, with greater confidence of rainfall decreases across the southwest and southeast of continental Australia (including the eastern seaboard) under a high greenhouse gas emission scenario ${ }^{91}$. The topographic effects of mountains in southeast Australia may further intensify rainfall deficits in winter and spring and increase rainfall in summer beyond what is simulated in global-scale models that cannot adequately resolve topography ${ }^{93}$. Models further produce robust future trends towards longer seasonal droughts in southern Australia but do not agree on changes in annual-scale droughts ${ }^{94}$. Future drying of Australia's mid-latitudes in winter is congruent with the projected greenhouse gas-driven positive trend in the SAM in this season ${ }^{31,91}$. However, drying of the Southern Hemisphere subtropics also appears to be a temporary response to rapid climate warming that ceases soon after global temperature stabilises ${ }^{95}$, meaning that ambitious climate change mitigation has the potential to reverse the precipitation loss expected across southern Australia. Thus, projected precipitation declines in winter and spring are likely to increasingly precondition southeast Australia (and particularly Victoria) to forest fire by increasing fuel dryness. In the short-to-medium term, fuel loads could also increase in association with forest dieback in response to declining cool season rainfall and increased heat stress ${ }^{11,96}$, while climate-related forest dieback might ultimately reduce fuel loads in the longer-term in some currently forested regions. Changes in summer precipitation remain unclear, so it is not possible to draw meaningful conclusions about the expected impact of summer rainfall on future fire risk.

Future changes are expected in tropical climate variability, with implications for fire risk (Fig. 7). Extreme El Niño and La Niña events may become more frequent through the twenty-first century ${ }^{97-99}$, continuing the significant trend towards higher ENSO variability that is reconstructed from palaeoclimate data ${ }^{64}$. The reconstructed and observed increase in positive IOD events since the 1960s is also expected to continue ${ }^{45}$. Events of similar magnitude to the 2019 positive IOD event are projected to become three times more frequent in the twenty-first century compared to the twentieth century under a high greenhouse gas emission scenario ${ }^{100}$, but this increase could be limited through climate change mitigation consistent with the ambitions of the Paris Agreement ${ }^{101}$. There are uncertainties in the ability of models to accurately simulate future ENSO and IOD variability. Nevertheless, the agreement between independent data sources (palaeoclimate, observations and models) on twentieth century changes, as well as the tight coupling between changes in the magnitude of ENSO and IOD during the last millennium ${ }^{53}$, gives moderate confidence in future projections of an increasing frequency of extreme ENSO and positive IOD events. Together this evidence suggests that the potential exists for more frequent years with extreme hot and dry conditions in southeast Australia, beyond that expected from mean temperature and rainfall trends alone. If this potential is realised, fuels in southeast Australia will be dry from winter to summer more often, and dangerous fire weather during fire seasons will occur more frequently.

Projections further indicate significant increases in the number of days conducive to extreme pyroconvective fire development for some parts of southern and southeastern Australia under a high greenhouse gas emission future ${ }^{16,17}$. In other parts of eastern and northeastern Australia decreases in pyroconvective risk are also possible in the future ${ }^{17}$. The increases in southeast Australia are related to projected drying of the air in the lower troposphere $(850 \mathrm{hPa})$ based on temperature-related changes in dewpoint depression ${ }^{16,17}$. These trends are most evident in spring, which could see pyroconvective risk developing earlier in the fire season than currently observed. However, rugged topography is also an important factor in pyroconvective fire development ${ }^{16}$, meaning that existing global climate model ensembles will not accurately reproduce the spatial characteristics and magnitude of future trends in extreme fire risk. Global models also do not currently resolve the synoptic-scale structures of deep cold fronts and strong pre-frontal winds that are important for extreme fires with the same fidelity as downscaled regional models ${ }^{102}$. There is some evidence that these extreme frontal events will become more frequent in southern Australia, particularly in a high greenhouse gas emission future, but there is also a large degree of variation between models in addition to high levels of natural variability 102,103 . During 2019, the sudden stratospheric warming event allowed for a sustained, multi-month equatorward shift in the frontal activity associated with the westerly jet ${ }^{51}$, but there is currently no information available on whether such Antarctic climate events could become more or less common with ongoing anthropogenic climate change. Finally, lightning is not resolved in climate models, making it difficult to assess climate changerelated changes in forest fire ignitions by lightning strikes ${ }^{104,105}$. Perhaps more important, though, are projected increases in climate conditions conducive to the development of extreme fire events in southeast Australia, as the potential for further fire ignitions from strong fronts, as well as lighting and ember spotting associated with pyroconvective fires has been observed and modelled ${ }^{106,107}$.

The multiple climate change contributors to fire risk in southeast Australia raise the possibility that fire events may 
rapidly intensify in the future. Observed threshold behaviour between fuel dryness and fire potential (Box 1), the apparent growing risk for normal forest fires to escalate into extreme pyroconvective firestorms (Supplementary Fig. 3), and the observed exponential intensification of fire radiative power to linear increases in fire risk indices (Fig. $5 \mathrm{c}, \mathrm{f}$ ), all add to this concern. The extreme 2019/20 fire season in southeast Australia (Supplementary Figs. 1 and 3) may be testament not only to climate change influences already observed (Fig. 6), but also highlights that fire risks in southeast Australia could increase more rapidly than previously anticipated from some climate model projections ${ }^{19}$.

\section{Broader context and response options}

This review has focused on forest fires in southeast Australia. However, climate variability and change are essential for understanding the past, current and future potential of fire regimes the world over. For example, $\mathrm{CO}_{2}$ fertilisation and high summer rainfall events have the potential to increase fuel loads and promote more widespread burning in the arid grasslands and savanna landscapes of northern Australia ${ }^{108-110}$. Increasingly frequent re-burning of forested areas in southeast Australia also has the potential to irreversibly alter ecosystem composition and biodiversity ${ }^{12,111}$. Around the world, an increasing number of studies are documenting climate-related changes in fire activity ${ }^{38,112,113}$, including quantification of the increased fire risk that is attributable to human-caused climate change ${ }^{80}$.

A Royal Commission initiated after Australia's Black Summer fire disaster pointed to an urgent need to improve disaster management capabilities and capacity in Australia in order to respond to more frequent, intense, complex and costly natural disasters under a changing climate ${ }^{114}$. The management of anticipated increases in fire risk can involve actions to: (i) limit the vulnerability of communities and ecosystems to fire hazards, (ii) limit the exposure of communities and ecosystems to fire hazards, and/or (iii) limit the hazard itself. Examples of the adaptation strategies that can be, or have been, employed to reduce fire risk include improved community information and fire preparedness (reduced vulnerability), improved development planning, building standards and management of the foresturban boundary (reduced exposure), and land management that reduces the fire switches (Box 1) required for large fires to develop or firefighting to extinguish fires once they start (reduced hazard). Hazard reduction burns are an adaptation measure that is widely used to reduce forest fire risk in Australia by managing fuel load. Climate change impacts on temperature and fuel moisture in southeast Australia are expected to decrease the capacity to carry out hazard reduction burns in autumn, but increase the ability to carry out these burns in winter instead $^{115,116}$. The importance of fuel dryness in preconditioning forest flammability provides information for early warning and preparedness for extreme fires ${ }^{117}$. Similarly, the importance of interannual climate variability in determining extreme years (Fig. 3) upon a background of rising fire risk means that seasonal forecasting is important for early warning on the scale of months ahead of the main fire season in southeast Australia. Recommendations of the Royal Commission to support better disaster risk management decisions included improving national systems of collecting and sharing bushfire related information, including information on climate change projections and fuel load management ${ }^{114}$. However, populations in southeast Australia are among the most exposed in the world to economically or socially disastrous fires ${ }^{118}$, and it is important to recognise that limits to adaptation exist. Disaster risk management is expected to become increasingly challenging and less effective as ongoing climate change moves regional climate and fire regimes outside of the range of human experience ${ }^{15,107,119}$.

Australia's Black Summer is consistent with scientific assessments that human-caused climate warming is virtually certain to increase the duration, frequency and intensity of forest fires in southeast Australia ${ }^{15,79}$. Limitations currently exist in the ability to model fire and some aspects of the weather and climate conditions that contribute to fire risk in southeast Australia. Nevertheless, it is clear that the contribution of climate change to increasing fire risk would be less in a low greenhouse gas emission future compatible with the Paris Agreement than in higher emission scenarios ${ }^{77,83}$. Pursuing ambitious global mitigation efforts alongside national and local adaptation measures would provide the best strategy for limiting further increases in fire risk in southeast Australia.

\section{Methods}

Climate data sets, monitoring and outlooks. The scope of this review covers the Australian states of New South Wales (NSW), the Australian Capital Territory (ACT) and Victoria, where the majority $(80 \%)$ of large and extreme fires burnt during Australia's Black Summer (Fig. 1a). The term "southeast" Australia is used in this study to describe the combined area covered by these states.

The temperature and rainfall data sets used in this study (Figs. 2, 3 and 5) come from the Australian Bureau of Meteorology (BOM). Monthly mean maximum temperature $\left(T_{\max }\right)$ is from the Australian Climate Observations Reference Network-Surface Air Temperature (ACORN-SAT version 2) data set that begins in 1910 (http://www.bom.gov.au/climate/data/acorn-sat/) ${ }^{120}$. Rainfall data are from the high-resolution gridded data set developed for the Australian Water

Availability Project (AWAP) that begins in 1900 (http://www.bom.gov.au/climate/ change/about/rain_timeseries.shtml) ${ }^{121}$. AWAP and ACORN-SAT version 2 are both gridded at $0.05^{\circ} \times 0.05^{\circ}$ resolution. The relative humidity data used with $T_{\max }$ for calculating FMI (Fig. 5) and VPD (Fig. 6) are as described for use in the gridded FFDI data ${ }^{43}$, derived from an observations-based data set throughout Australia ${ }^{121}$

Descriptions of the development of the current drought in NSW are derived from the combined drought indicators used by the NSW Department of Primary Industries (DPI) through their Enhanced Drought Information System (https:// edis.dpi.nsw.gov.au/). The combined drought indicators use three indices to determine drought category at a given time. These include a rainfall index (meteorological drought), a soil water index (hydrological drought) and a plant growth index (agronomic drought). Archives of seasonal updates issued by the NSW DPI indicate that all of the state of NSW was experiencing drought in at least one of the three drought categories by July 2018 (https://www.dpi.nsw.gov.au/ climate-and-emergencies/seasonal-conditions/ssu/july-2018).

The BOM annual climate statement describes 2019 as Australia's hottest and driest year on record (http://www.bom.gov.au/climate/current/annual/aus/2019/). Details of the record-breaking heat experienced in December 2019 are also included in Special Climate Statement 73 from the BOM (http://www.bom.gov.au/ climate/current/statements/scs73.pdf). Information about key modes of variability are included in the BOM seasonal outlooks for Australian climate. In 2019 the development of a positive IOD event was reported in seasonal forecasts from as early as May (http://www.bom.gov.au/climate/ahead/outlooks/archive/20190516outlook.shtml), and from September the prolonged negative SAM also formed part of the seasonal climate advice (http://www.bom.gov.au/climate/ahead/outlooks/ archive/20190905-outlook.shtml). Warm and dry conditions, including the current drought and the developing IOD, all contributed to the Australian Seasonal Bushfire Outlook in August 2019, where large areas of above normal fire potential were identified in southeast Australia (https://www.bnhcrc.com.au/hazardnotes/ 63). The risk areas identified in this hazard briefing well represented the areas where large and extreme forest fires developed over the subsequent Black Summer (Fig. 1a).

Climate indices (Fig. 3) for ENSO and the IOD were calculated from the Extended Reconstructed Sea Surface Temperature (ERSST) v5 data set ${ }^{122}$. ENSO indices were used from 1950 onwards, recognising that large uncertainties exist for tropical SST data sets prior to this time ${ }^{123}$. Likewise, IOD indices were used from 1958 onwards due to a lack of observational input data from the key IOD regions prior to this time ${ }^{45}$. We use the Niño4 index for ENSO variability, which is calculated as the mean SST anomaly in the region spanning $5^{\circ} \mathrm{N}$ to $5^{\circ} \mathrm{S}, 160^{\circ} \mathrm{E}$ to $150^{\circ} \mathrm{W}$. The Dipole Mode Index represents IOD variability and is calculated as the difference in mean SST anomalies between the equatorial western $\left(50^{\circ} \mathrm{E}\right.$ to $70^{\circ} \mathrm{E}$, $10^{\circ} \mathrm{N}$ to $\left.10^{\circ} \mathrm{S}\right)$ and eastern $\left(90^{\circ} \mathrm{E}\right.$ to $110^{\circ} \mathrm{E}, 0^{\circ}$ to $\left.10^{\circ} \mathrm{S}\right)$ Indian Ocean. The SAM Index is calculated as the difference in observed mean sea level pressure anomalies (normalised) between the southern mid-latitudes $\left(40^{\circ} \mathrm{S}\right)$ and Antarctica $\left(65^{\circ} \mathrm{S}\right)$. We use the Marshall SAM Index ${ }^{124}$ that begins in 1957 (http://www.nerc-bas.ac.uk/icd/ gjma/sam.html). 
Historical and observational fire data sets. Historical data of major fire events (Figs. 2 and 3c) in southeast Australia was compiled from NSW and Victorian government reports. These reports were sourced from:

https://www.parliament.nsw.gov.au/researchpapers/Documents/bushfires-innsw-timelines-and-key-sources/Bushfires\%20in\%20NSW\%20-\%20timelines\% 20and\%20key\%20sources.pdf

http://www.bushfireeducation.vic.edu.au/verve/_resources/

Bushfires_in_our_History.pdf

https://www.ffm.vic.gov.au/history-and-incidents/past-bushfires

The forest fire burnt area for each fire season was compiled from these reports, excluding descriptions of predominantly grass and scrub fires. Major fire years were classified as years where these historical documents indicated that 0.5 million hectares or more of forest in southeast Australia was burnt.

Data since 2011, including summaries of burnt forest area for the 2019/20 fire season, are from the Australian Government Department of Agriculture Water and Environment:

https://www.agriculture.gov.au/abares/forestsaustralia/forest-data-maps-andtools/fire-data

These records indicate that $80 \%$ of the forest area burnt during the $2019 / 20$ fire season occurred in the southeast Australian states of NSW, ACT and Victoria. In these states, $23.6 \%$ of their 27.7 million hectares of native forest was burnt during the Black Summer fires.

We also used Fire Radiative Power (FRP) ${ }^{125}$ measurements to compare the strength of the 2019/20 fires to past events. We used daytime and night-time FRP data from the MODIS instruments, which operate onboard the Terra and Aqua polar orbiting satellites. Each deliver measurements with a $1 \mathrm{~km}$ spatial resolution and are capable of detecting the FRP from actively burning fires covering as little as $0.1-0.01 \%$ of the pixel area. We calculated daily (Supplementary Fig. 1) and monthly (Fig. 5 and Supplementary Fig. 1) FRP totals for all fires in the target region between September 2019 and February 2020, comparing this to the 2003/04 to 2018/19 mean and maxima of FRP for the same spring and summer intervals. MODIS FRP data were taken from the NASA FIRM system, which is based upon the MODIS active fire detection algorithm detailed in ref. ${ }^{126}$. FRP is considered linearly proportional to combustion rate ${ }^{125}$, so higher daily (or monthly) FRP totals represent greater amounts of material being consumed by the fires.

Fire risk indices. Dead fuel moisture levels in southeast Australian forests can be monitored based on a vapour pressure deficit model ${ }^{127,128}$ defined as:

$$
\text { where: } \quad \begin{aligned}
\operatorname{Dead} \mathrm{FM}(\%) & =6.79+27.43 \mathrm{e}^{-1.05 V P D}, \\
V P D & =\text { vapour pressure deficit }(\mathrm{kPa})
\end{aligned}
$$

Vapour pressure deficit is, in turn, a function of relative humidity and temperature. The Dead FM index has been trained on fuel moisture contents ranging from $5-60 \%$, but its form means that the model becomes insensitive for very dry fuels $(<6.79 \%)$.

The Fuel Moisture Index (FMI) ${ }^{129,130}$ is an alternate index that can be used to represent the dryness of fuels based directly on temperature and relative humidity. FMI is a dimensionless index defined as:

$$
\text { where: } \quad \begin{aligned}
T & =\text { surface air temperature }\left({ }^{\circ} \mathrm{C}\right) \\
\mathrm{RH} & =\text { relative humidity }(\%)
\end{aligned}
$$

FMI is not effective for describing wet fuels, does not incorporate effects of rainfall on fuel moisture, and should not be considered as giving a quantified estimate of fuel moisture content without the use of a scaling factor ${ }^{129}$. However, it is simple to calculate making it easy to implement operationally, is effective at emulating the predictions of more complex process-based fuel moisture models for different types of fuels ${ }^{129}$, and does not lose sensitivity at low fuel moisture levels, and so may be a better indicator than other models of the critically low fuel moisture conditions that are an important factor in the development of extreme fires.

The Forest Fire Danger Index (FFDI) ${ }^{131}$ is commonly used to represent the influence of surface weather conditions on bushfire risk in eucalypt forests, and is based on temperature, wind speed, humidity and a drought factor. The FFDI values used in this study are based on calculations and data sets as described in ref. ${ }^{43}$. The index is calculated as:

$$
\text { FFDI }=\exp ^{(0.0338 T-0.0345 \mathrm{RH}+0.0234 v+0.243147)} \times \mathrm{DF}^{0.987}
$$

where: $\quad T=$ daily maximum surface air temperature $\left({ }^{\circ} \mathrm{C}\right)$

$$
\mathrm{RH}=\text { relative humidity }(\%)
$$$$
v=\text { wind speed }\left(\mathrm{km} \mathrm{h}^{-1}\right)
$$

$\mathrm{DF}=$ a drought factor to represent fuel dryness that is based on temporally accumulated soil moisture deficit calculated using the Keetch-Byram Drought Index (KBDI) and the past 20 days rainfall 75

The FFDI is used operationally in Australia as an indicator of fire danger. It performs an analogous role to indices used in other countries, such as the Canadian
Fire Weather Index (FWI) developed for pine forests ${ }^{132-134}$. The FFDI and other fire danger rating systems ${ }^{132,135}$ are used for a wide variety of operational purposes by meteorologists and fire managers, such as declaring fire weather warnings and predicting fire properties such as rate of spread, intensity and suppression difficulty. FFDI suffers from some limitations that are relatively well understood, such as the omission of important local risk factors (e.g., topography and vegetation type) and potentially important upper atmospheric conditions ${ }^{136}$, and the fact it was developed by necessity in the absence of extreme fire weather conditions ${ }^{137}$. The KBDI used within the drought factor term has also been shown to be a poor proxy for fuel moisture alone, and should not be viewed as a substitute for specific estimates of fuel moisture ${ }^{127}$. Nevertheless, FFDI has consistently been found to be an important predictor of various aspects of fire and its effects, including severity ${ }^{107}$, house loss ${ }^{138,139}$ and life loss ${ }^{140}$.

The FFDI is constructed from easily measured climate parameters that play a role, either directly or indirectly, in moderating fire risk. This relationship was developed using observational data before global warming intensified ${ }^{131,141}$. Extreme fire danger exceeding the limits of the operational range of the FFDI during the 2003 Canberra fires and the 2009 Black Saturday fires recently led to the addition of a Catastrophic rating (FFDI $\geq 100$; also referred to as Code Red in Victoria). The FFDI is based on a statistical relationship, rather than on equations that reflect the actual physical processes that increase fire danger, so it is not clear whether the FFDI will continue to be a good indicator of fire danger in a changing climate where temperatures are rising rapidly. However, the FFDI has continued to provide a good indication of fire danger in recent years, including the unprecedented conditions in 2019/20 (Fig. 5 and Supplementary Fig. 3)

The continuous Haines (C-Haines) index ${ }^{136}$ is used in Australia in addition to the FFDI to describe the potential for vertical atmospheric stability and humidity to influence the development of dangerous fires and pyroconvective processes ${ }^{16,17,136}$. The index is calculated as:

\section{$\mathrm{C}$-Haines $=\mathrm{CA}+\mathrm{CB}$}

$\mathrm{CA}$ is a stability term calculated from the difference in air temperature at the 850 and $700 \mathrm{hPa}$ levels. $\mathrm{CB}$ is a humidity term from the dewpoint depression at $850 \mathrm{hPa}$, which is equal to the temperature at $850 \mathrm{hPa}$ minus the dewpoint temperature at $850 \mathrm{hPa}$.

Monte Carlo testing. Monte Carlo (MC) testing was used to test whether rainfall anomalies in the past 2 decades in southeast Australia are unusual in the context of unforced variability (Fig. 2 and Supplementary Fig. 2). The MC analysis was carried out across moving 20-year windows, examining the number of below average rainfall years and the 20-year accumulated precipitation anomalies. A 20-year window was chosen based on the observation that 15 of the last 20 years have experienced below average mean annual rainfall in southeast Australia (Fig. 2b). Tests were carried out both for mean annual rainfall, and for cool season (April-September) mean rainfall.

The MC tests used 10,000 synthetic time series with the same length (1900-2019), lag-1 autocorrelation, and standard deviation as the observed rainfall record for southeast Australia. Each MC series was expressed as a precipitation anomaly relative to the 1961-1990 climatology of that series. Moving 20-year windows were then used to calculate the number of below average rainfall years and the accumulated precipitation anomaly. Percentiles were calculated across the length and number of MC series in order to estimate the 5th and 95th percentiles of 20-year rainfall anomalies and number of below average years expected based on the properties of the observational rainfall record. For mean annual rainfall, the number of below average rainfall years and the accumulated precipitation deficits in the past 20 years are marginally significant in the MC tests ( $\sim 95 \%$ level), but are not unprecedented in a historical context (Supplementary Fig. 2). In contrast, accumulated cool season rainfall deficits in the last 20 years, and the number of cool seasons with below average rainfall, are highly significant relative to the MC testing and are unprecedented in the historical record (Supplementary Fig. 2).

MC testing was also applied to test whether fire-promoting modes of variability have historically coincided with years when large fires burnt in southeast Australia more often than would be expected by chance alone (Fig. 3c). The data were assessed across 63 years (1957-2019), based on when reliable observational climate data are available from. Across these 63 years, there are 14 years where historical documents indicate that 0.5 million hectares or more was burnt in forests across southeast Australia. Active phases of the modes of variability were determined using detrended data, with event thresholds relative to the 1961-1990 mean and standard deviation of monthly data. Over the 63-year period there are 14 years where the July-March mean of the Niño4 Index was more than $+1 \sigma$ above the mean, and 12 years more than $-1 \sigma$ below the mean. For the Dipole Mode Index there are 10 years where the July-December mean was more than $+1 \sigma$ above the mean, and 12 years more than $-1 \sigma$ below the mean. For the SAM Index there are 10 years where the warm season (October-March) mean was more than $+0.5 \sigma$ above the mean, and 17 years more than $-0.5 \sigma$ below the mean. A lower event threshold is used for the SAM due to the low persistence of atmospheric SAM anomalies compared to the coupled ocean-atmosphere modes of ENSO and the IOD.

MC testing was performed by constructing 10,000 synthetic time series of 63 years length and with random distributions of the same number of large fire years and climate mode events as in the historical record. The 5-95\% range of MC results 
was used to estimate what can be expected by chance, and observations outside this range are considered significant. Of the 14 large fire years in the observational record, 3 years had no climate modes in fire-promoting phases (4-9 years expected by chance), 5 years had 1 mode in a fire-promoting phase (3-9 years expected by chance), 5 years had 2 co-occurring modes in fire-promoting phases $(0-3$ years expected by chance), and 1 year had all three modes co-occurring in fire-promoting phases $(0-1$ years expected by chance).

Conversely, of the 49 years with only small or no fires in the observational record there were 30 years that had no climate modes in fire-promoting phases (20-27 years expected by chance), 15 years had 1 mode in a fire-promoting phase (15-25 years expected by chance), 4 years had 2 co-occurring modes in firepromoting phases (2-8 years expected by chance), and none had all three modes co-occurring in fire-promoting phases ( $0-2$ years expected by chance).

The MC testing thus indicates that having none of the modes of variability in their fire-promoting phase significantly reduces the chance of having extensive fires in southeast Australia, relative to a random process $(p<0.05$; noting that this assessment does not preclude smaller but high impact fires). The co-occurrence of 2 modes in their fire-promoting phases, as occurred in 2019, significantly increases the chances of experiencing extensive fires in southeast Australia, relative to what would be expected by chance $(p<0.05)$.

Time of emergence. The emergence of signals of long-term change was assessed using observational indices (FFDI, KBDI) and climate factors (VPD) related to fire risk (Fig. 6 and Supplementary Fig. 4). Time of Emergence involves using the variability (noise) within a reference interval to test when long-term signals emerge above the noise threshold ${ }^{142}$. For this assessment we use the 50 -year interval from 1950-1999 as the reference interval, and calculate the noise levels as $1 \sigma$ and $2 \sigma$ of annual (Fig. 6) or seasonal (Supplementary Fig. 4) values above or below the mean in this reference interval. The signal is calculated as a 30 -year lowess filter. This analysis likely underestimates the true level of emergence from pre-industrial variability as the gridded observational data needed for fire danger indicators is only available since the mid-twentieth century ${ }^{43}$.

\section{Data availability}

The data sets analysed in this review are cited in the appropriate sections of the manuscript text and methods, including government web links.

Received: 7 May 2020; Accepted: 17 November 2020; Published online: 07 January 2021

\section{References}

1. Boer, M. M., Resco de Dios, V. \& Bradstock, R. A. Unprecedented burn area of Australian mega forest fires. Nat. Clim. Chang. 10, 171-172 (2020).

Demonstrates that the 2019-2020 mega fires in Australia were unprecedented in scale, both nationally and globally.

2. Nolan, R. H. et al. Causes and consequences of eastern Australia's 2019-20 season of mega-fires. Glob. Chang. Biol. 26, 1039-1041 (2020).

3. Filkov, A. I., Ngo, T., Matthews, S., Telfer, S. \& Penman, T. D. Impact of Australia's catastrophic 2019/20 bushfire season on communities and environment. Retrospective analysis and current trends. J. Safe. Sci. Resil. 1, 44-56 (2020).

4. Sharples, J. J. et al. Natural hazards in Australia: extreme bushfire. Clim. Chang. 139, 85-99 (2016).

5. Kablick, G. P. I., Allen, D. R., Fromm, M. D. \& Nedoluha, G. E. Australian pyroCb smoke generates synoptic-scale stratospheric anticyclones. Geophys. Res. Lett. 47, e2020GL088101 (2020).

6. Ward, M. et al. Impact of 2019-2020 mega-fires on Australian fauna habitat. Nat. Ecol. Evol. 4, 1321-1326 (2020).

7. Borchers Arriagada, N. et al. Unprecedented smoke-related health burden associated with the 2019-20 bushfires in eastern Australia. Med. J. Aust. 213, 282-283 (2020).

8. Bryant, R. A. et al. Psychological outcomes following the Victorian Black Saturday bushfires. Aust. N. Z. J. Psychiatry 48, 634-643 (2014).

9. State of NSW Department of Planning Industry and Environment. NSW Fire and the Environment 2019-20 Summary: Biodiversity and landscape data and analyses to understand the effects of fire events. 20pp. (NSW Government, 2020).

10. Bowman, D. M. J. S. Australian Rainforests: Islands of Green in a Land of Fire. (Cambridge University Press, 2000).

11. De Kauwe, M. G. et al. Identifying areas at risk of drought-induced tree mortality across South-Eastern Australia. Glob. Chang. Biol. 26, 5716-5733 (2020).

12. Lindenmayer, D. B. \& Taylor, C. New spatial analyses of Australian wildfires highlight the need for new fire, resource, and conservation policies. Proc. Natl Acad. Sci. USA 117, 12481 (2020). Policy recommendations for human and natural systems impacted by Australian forest fires, including implications of frequent re-burning in some areas.
13. Read, P. \& Denniss, R. With costs approaching $\$ 100$ billion, the fires are Australia's costliest natural disaster. Conversation (2020). https:// theconversation.com/with-costs-approaching-100-billion-the-fires-areaustralias-costliest-natural-disaster-129433.

14. Jones, M. W. et al. Climate change increases the risk of wildfires. (University of East Anglia, https://sciencebrief.org/briefs/wildfires, 2020).

15. Reisinger, A. et al. in Climate Change 2014: Impacts, Adaptation, and Vulnerability. Part B: Regional Aspects. Contribution of Working Group II to the Fifth Assessment Report of the Intergovernmental Panel on Climate Change. (eds V. R. Barros et al.) Ch. 25, 1371-1438 (Cambridge University Press, 2014).

16. Di Virgilio, G. et al. Climate change increases the potential for extreme wildfires. Geophys. Res. Lett. 46, 8517-8526 (2019). Detailed description of the climate and landscape factors that allow forest fires to develop into extreme (pyroCb) fires in southeast Australia.

17. Dowdy, A. J. et al. Future changes in extreme weather and pyroconvection risk factors for Australian wildfires. Sci. Rep. 9, 10073 (2019). Assessment of observed and future changes in indicators for the dangerous weather conditions that promote large and extreme fires in Australia.

18. Garnaut, R. Projecting Australian climate change. Garn. Clim. Chang. Rev. 5, 105-120 (2008).

19. Abatzoglou, J. T., Williams, A. P. \& Barbero, R. Global emergence of anthropogenic climate change in fire weather indices. Geophys. Res. Lett. 46, 326-336 (2019).

20. IPCC. Summary for Policymakers. in Global Warming of $1.5^{\circ} \mathrm{C}$. An IPCC Special Report on the Impacts of Global Warming of $1.5^{\circ} \mathrm{C}$ above Pre-industrial Levels and Related Global Greenhouse Gas Emission Pathways, in the Context of Strengthening the Global Response to the Threat of Climate Change, Sustainable Development, and Efforts to Eradicate Poverty (eds MassonDelmotte, V. et al.) 32 pp. (World Meteorological Organization 2018).

21. Bureau of Meteorology and CSIRO. State of the Climate. (www.bom.gov.au/ state-of-the-climate, 2018)

22. IPCC. Summary for Policymakers. in Climate Change 2013: The Physical Science Basis. Contribution of Working Group I to the Fifth Assessment Report of the Intergovernmental Panel on Climate Change (eds Stocker, T. F. et al.) (Cambridge University Press, 2013).

23. Nguyen, H. et al. Using the evaporative stress index to monitor flash drought in Australia. Environ. Res. Lett. 14, 064016 (2019).

24. Pendergrass, A. G. et al. Flash droughts present a new challenge for subseasonal-to-seasonal prediction. Nat. Clim. Chang. 10, 191-199 (2020).

25. Lim, E.-P. \& Hendon, H. H. Causes and predictability of the negative indian ocean dipole and its impact on La Niña during 2016. Sci. Rep. 7, 12619 (2017).

26. Ummenhofer, C. C. et al. What causes southeast Australia's worst droughts? Geophys. Res. Lett. 36, L04706 (2009).

27. King, A. D., Pitman, A. J., Henley, B. J., Ukkola, A. M. \& Brown, J. R. The role of climate variability in Australian drought. Nat. Clim. Chang. 10, 177-179 (2020). Changes the framing of drought in southeast Australia based on the time since drought breaking rain associated with rain-promoting phases of tropical climate variability.

28. Ukkola, A. M., Roderick, M. L., Barker, A. \& Pitman, A. J. Exploring the stationarity of Australian temperature, precipitation and pan evaporation records over the last century. Environ. Res. Lett. 14, 124035 (2019).

29. Timbal, B. \& Drosdowsky, W. The relationship between the decline of Southeastern Australian rainfall and the strengthening of the subtropical ridge. Int. J. Climatol. 33, 1021-1034 (2013).

30. Hendon, H. H., Thompson, D. W. J. \& Wheeler, M. C. Australian rainfall and surface temperature variations associated with the southern hemisphere annular mode. J. Climat. 20, 2452-2467 (2007).

31. Gillett, N. P. \& Fyfe, J. C. Annular mode changes in the CMIP5 simulations. Geophys. Res. Lett. 40, 1189-1193 (2013).

32. Delworth, T. L. \& Zeng, F. Regional rainfall decline in Australia attributed to anthropogenic greenhouse gases and ozone levels. Nat. Geosci. 7, 583-587 (2014).

33. Pepler, A. Record lack of cyclones in southern Australia during 2019. Geophys. Res. Lett. 47, e2020GL088488 (2020).

34. Dowdy, A. J. Climatology of thunderstorms, convective rainfall and dry lightning environments in Australia. Clim. Dynam. 54, 3041-3052 (2020).

35. Yin, D., Roderick, M. L., Leech, G., Sun, F. \& Huang, Y. The contribution of reduction in evaporative cooling to higher surface air temperatures during drought. Geophys. Res. Lett. 41, 7891-7897 (2014).

36. Nicholls, N. The changing nature of australian droughts. Clim. Chang. 63 , 323-336 (2004)

37. Williams, A. P. et al. Large contribution from anthropogenic warming to an emerging North American megadrought. Science 368, 314 (2020).

38. Williams, A. P. et al. Observed impacts of anthropogenic climate change on wildfire in California. Earth's Fut. 7, 892-910 (2019).

39. Miralles, D. G., Teuling, A. J., van Heerwaarden, C. C. \& Vilà-Guerau de Arellano, J. Mega-heatwave temperatures due to combined soil desiccation and atmospheric heat accumulation. Nat. Geosci. 7, 345-349 (2014). 
40. Holgate, C. M., Evans, J. P., Van Dijk, A. I. J. M. \& Pitman, A. J. Australian precipitation recycling and evaporative source regions. J. Clim. 33, 8721-8735 (2020).

41. Williamson, G. J. et al. Measurement of inter- and intra-annual variability of landscape fire activity at a continental scale: the Australian case. Environ. Res. Lett. 11, 035003 (2016).

42. Harris, S. \& Lucas, C. Understanding the variability of Australian fire weather between 1973 and 2017. PLoS ONE 14, e0222328 (2019).

43. Dowdy, A. J. Climatological variability of fire weather in Australia. J. Appl. Meteorol. Climatol. 57, 221-234 (2018). Definitive record of fire weather conditions in Australia, as described by the Forest Fire Danger Index.

44. Allan, R. J., Gergis, J. \& D'Arrigo, R. D. Placing the AD 2014-2016 'protracted' El Niño episode into a long-term context. Holocene 30, 90-105 (2019).

45. Abram, N. J. et al. Palaeoclimate perspectives on the Indian ocean dipole. Quater. Sci. Rev. 237, 106302 (2020). Review demonstrating historically significant increase in the frequency and intensity of (fire-promoting) positive Indian Ocean Dipole events that is expected to continue in the future.

46. Saji, N. H., Goswami, B. N., Vinayachandran, P. N. \& Yamagata, T. A dipole mode in the tropical Indian Ocean. Nature 401, 360-363 (1999).

47. Webster, P. J., Moore, A. M., Loschnigg, J. P. \& Leben, R. R. Coupled ocean-atmosphere dynamics in the Indian Ocean during 1997-98. Nature 401, 356-360 (1999).

48. Cai, W., Cowan, T. \& Raupach, M. Positive Indian Ocean Dipole events precondition southeast Australia bushfires. Geophys. Res. Lett. 36, https://doi. org/10.1029/2009GL039902 (2009).

49. Arblaster, J. M. \& Meehl, G. A. Contributions of external forcings to southern annular mode trends. J. Clim. 19, 2896-2905 (2006).

50. Thompson, D. W. J. et al. Signatures of the Antarctic ozone hole in Southern Hemisphere surface climate change. Nat. Geosci. 4, 741-749 (2011).

51. Lim, E.-P. et al. Australian hot and dry extremes induced by weakenings of the stratospheric polar vortex. Nat. Geosci. 12, 896-901 (2019). Demonstrates the effect of sudden stratospheric warming events over Antarctica on climate extremes and fire danger in southeast Australia.

52. Cai, W. et al. Pantropical climate interactions. Science 363, eaav4236 (2019).

53. Abram, N. J. et al. Coupling of Indo-Pacific climate variability over the last millennium. Nature 579, 385-392 (2020).

54. Abram, N. J. et al. Evolution of the Southern Annular Mode during the past millennium. Nat. Clim. Chang. 4, 564-569 (2014).

55. Dätwyler, C., Grosjean, M., Steiger, N. J. \& Neukom, R. Teleconnections and relationship between the El Niño-Southern Oscillation (ENSO) and the Southern Annular Mode (SAM) in reconstructions and models over the past millennium. Clim. Past 16, 743-756 (2020).

56. Bradstock, R. A. A biogeographic model of fire regimes in Australia: current and future implications. Glob. Ecol. Biogeogr. 19, 145-158 (2010). Landmark conceptual paper describing variation in Australian fire regimes and key drivers both now and in the future.

57. Mooney, S. D. et al. Late Quaternary fire regimes of Australasia. Quater. Sci. Rev. 30, 28-46 (2011). A review of charcoal evidence for Australia's fire history over the past 70,000 years, demonstrating strong links to climate changes across a range of temporal changes.

58. Marlon, J. R. et al. Climate and human influences on global biomass burning over the past two millennia. Nat. Geosci. 1, 697-702 (2008).

59. Pechony, O. \& Shindell, D. T. Driving forces of global wildfires over the past millennium and the forthcoming century. Proc. Natl Acad. Sci. 107, 19167 (2010).

60. Fletcher, M.-S., Hall, T. \& Alexandra, A. N. The loss of an indigenous constructed landscape following British invasion of Australia: An insight into the deep human imprint on the Australian landscape. Ambio, https://doi.org/ 10.1007/s13280-020-01339-3 (2020).

61. Daniau, A. L. et al. Predictability of biomass burning in response to climate changes. Glob. Biogeochem. Cycles 26, https://doi.org/10.1029/2011GB004249 (2012).

62. Fletcher, M.-S. et al. Centennial-scale trends in the Southern Annular Mode revealed by hemisphere-wide fire and hydroclimatic trends over the past 2400 years. Geology 46, 363-366 (2018).

63. Battistel, D. et al. High-latitude Southern Hemisphere fire history during the mid- to late Holocene (6000-750 BP). Clim. Past 14, 871-886 (2018).

64. Grothe, P. R. et al. Enhanced El Niño-Southern oscillation variability in recent decades. Geophys. Res. Lett. 47, e2019GL083906 (2020). Demonstrates that El Niño-Southern Oscillation variability has become significantly stronger in the past 50 years compared with natural variability over the past 7,000 years.

65. Freund, M. B. et al. Higher frequency of Central Pacific El Niño events in recent decades relative to past centuries. Nat. Geosci. 12, 450-455 (2019).

66. Dätwyler, C. et al. Teleconnection stationarity, variability and trends of the Southern Annular Mode (SAM) during the last millennium. Clim. Dynam. 51, 2321-2339 (2018).

67. Goyal, R., England, M. H., Sen Gupta, A. \& Jucker, M. Reduction in surface climate change achieved by the 1987 Montreal Protocol. Environ. Res. Lett. 14, 124041 (2019)
68. Banerjee, A., Fyfe, J. C., Polvani, L. M., Waugh, D. \& Chang, K.-L. A pause in Southern Hemisphere circulation trends due to the Montreal Protocol. Nature 579, 544-548 (2020).

69. Nicholls, N. Detecting and attributing Australian climate change: a review. Aust. Meteorol. Magaz. 55, 199-211 (2006).

70. McRae, R. H. D., Sharples, J. J. \& Fromm, M. Linking local wildfire dynamics to pyroCb development. Nat. Hazards Earth Syst. Sci. 15, 417-428 (2015).

71. Khaykin, S. et al. The 2019/20 Australian wildfires generated a persistent smoke-charged vortex rising up to $35 \mathrm{~km}$ altitude. Commun. Earth Environ. 1, 22 (2020).

72. Reeder, M. J., Spengler, T. \& Musgrave, R. Rossby waves, extreme fronts, and wildfires in southeastern Australia. Geophys. Res. Lett. 42, 2015-2023 (2015)

73. Sharples, J. J., Mills, G. A., McRae, R. H. D. \& Weber, R. O. Foehn-like winds and elevated fire danger conditions in Southeastern Australia. J. Appl. Meteorol. Climatol. 49, 1067-1095 (2010).

74. Dowdy, A. J. \& Pepler, A. Pyroconvection risk in Australia: climatological changes in atmospheric stability and surface fire weather conditions. Geophys. Res. Lett. 45, 2005-2013 (2018).

75. Finkele, K., Mills, G. A., Beard, G. \& Jones, D. A. National daily gridded soil moisture deficit and drought factors for use in prediction of forest fire danger index in Australia. Bureau of Meteorology Research Centre research report 119, 68pp. (2006).

76. Vicente-Serrano, S. M., Beguería, S. \& López-Moreno, J. I. A Multiscalar Drought Index sensitive to global warming: the Standardized Precipitation Evapotranspiration Index. J. Clim. 23, 1696-1718 (2010).

77. Lucas, C., Hennessy, K., Mills, G. A. \& Bathols, J. Bushfire weather in southeast Australia: recent trends and projected climate change impacts. Vol. 80 (Bushfire Cooperative Research Centre, 2007).

78. Beer, T., Gill, A. M. \& Moore, P. H. R. in Greenhouse: Planning for Climatic Change (ed. Pearman, G. I.) 421-427 (CSIRO Publishing, 1988). A pioneering publication indicating that human-caused climate change would increase forest fire danger in Australia.

79. Hennessy, K. et al. Australia and NewZealand. in Climate Change 2007: Impacts, Adaptation and Vulnerability. Contribution of Working Group II to the Fourth Assessment Report of the Intergovernmental Panel on Climate Change (eds Parry, M. L. et al.) 507-540 (Cambridge University Press, 2007).

80. Barbero, R., Abatzoglou, J. T., Pimont, F., Ruffault, J. \& Curt, T. Attributing increases in fire weather to anthropogenic climate change over France. Front. Earth Sci. 8, 104 (2020).

81. Hantson, S. et al. Quantitative assessment of fire and vegetation properties in historical simulations with fire-enabled vegetation models from the Fire Model Intercomparison Project. Geosci. Model Dev. Discuss. 13, 3299-3318 (2020).

82. Sanderson, B. M. \& Fisher, R. A. A fiery wake-up call for climate science. Nat Clim. Chang. 10, 175-177 (2020).

83. Meinshausen, M. et al. The shared socio-economic pathway (SSP) greenhouse gas concentrations and their extensions to 2500. Geosci. Model Dev. 13, 3571-3605 (2020)

84. Clarke, H. et al. An investigation of future fuel load and fire weather in Australia. Clim. Chang. 139, 591-605 (2016).

85. Ukkola, A. M. et al. Reduced streamflow in water-stressed climates consistent with CO2 effects on vegetation. Nat. Clim. Chang. 6, 75-78 (2016).

86. Ellsworth, D. S. et al. Elevated $\mathrm{CO}_{2}$ does not increase eucalypt forest productivity on a low-phosphorus soil. Nat. Clim. Chang. 7, 279-282 (2017).

87. Jiang, $M$. et al. The fate of carbon in a mature forest under carbon dioxide enrichment. Nature 580, 227-231 (2020).

88. van der Sleen, P. et al. No growth stimulation of tropical trees by 150 years of $\mathrm{CO} 2$ fertilization but water-use efficiency increased. Nat. Geosci. 8, 24-28 (2015).

89. Yuan, W. et al. Increased atmospheric vapor pressure deficit reduces global vegetation growth. Sci. Adv. 5, eaax1396 (2019).

90. Novick, K. A. et al. The increasing importance of atmospheric demand for ecosystem water and carbon fluxes. Nat. Clim. Chang. 6, 1023-1027 (2016).

91. Grose, M. R. et al. Insights From CMIP6 for Australia's Future Climate. Earth's Fut. 8, e2019EF001469 (2020). Provides an up-to-date examination of the future projections of Australia's climate, based on state-of-the-art climate models.

92. Perkins-Kirkpatrick, S. E. \& Gibson, P. B. Changes in regional heatwave characteristics as a function of increasing global temperature. Sci. Rep. 7 , 12256 (2017).

93. Grose, M. R. et al. The role of topography on projected rainfall change in midlatitude mountain regions. Clim. Dynam. 53, 3675-3690 (2019).

94. Ukkola, A. M., De Kauwe, M. G., Roderick, M. L., Abramowitz, G. \& Pitman A. J. Robust future changes in meteorological drought in CMIP6 projections despite uncertainty in precipitation. Geophys. Res. Lett. 46, e2020GL087820 (2020). 
95. Sniderman, J. M. K. et al. Southern hemisphere subtropical drying as a transient response to warming. Nat. Clim. Chang. 9, 232-236 (2019).

96. Matusick, G., Ruthrof, K. X., Brouwers, N. C., Dell, B. \& Hardy, G. S. J. Sudden forest canopy collapse corresponding with extreme drought and heat in a mediterranean-type eucalypt forest in southwestern Australia. Eur. J. For. Res. 132, 497-510 (2013).

97. Cai, W. et al. Increasing frequency of extreme El Niño events due to greenhouse warming. Nat. Clim. Chang. 4, 111-116 (2014).

98. Cai, W. et al. Increased frequency of extreme La Niña events under greenhouse warming. Nat. Clim. Chang. 5, 132-137 (2015).

99. IPCC. Summary for Policymakers. in IPCC Special Report on the Ocean and Cryosphere in a Changing Climate (IPCC, 2019).

100. Cai, W. et al. Increased frequency of extreme Indian Ocean Dipole events due to greenhouse warming. Nature 510, 254-258 (2014).

101. Cai, W. et al. Stabilised frequency of extreme positive Indian Ocean Dipole under $1.5^{\circ} \mathrm{C}$ warming. Nat Commun. 9, 1419 (2018).

102. Grose, M. R., Fox-Hughes, P., Harris, R. M. B. \& Bindoff, N. L. Changes to the drivers of fire weather with a warming climate-a case study of southeast Tasmania. Clim. Chang. 124, 255-269 (2014).

103. Hasson, A. E. A., Mills, G. A., Timbal, B. \& Walsh, K. Assessing the impact of climate change on extreme fire weather events over southeastern Australia. Clim. Res. 39, 159-172 (2009).

104. Krause, A., Kloster, S., Wilkenskjeld, S. \& Paeth, H. The sensitivity of global wildfires to simulated past, present, and future lightning frequency. J. Geophys. Res.: Biogeosci. 119, 312-322 (2014).

105. Finney, D. L. et al. A projected decrease in lightning under climate change. Nat. Clim. Chang. 8, 210-213 (2018)

106. Dowdy, A. J., Fromm, M. D. \& McCarthy, N. Pyrocumulonimbus lightning and fire ignition on Black Saturday in southeast Australia. J. Geophys. Res.: Atmos. 122, 7342-7354 (2017).

107. Tolhurst, K. G. \& McCarthy, G. Effect of prescribed burning on wildfire severity: a landscape-scale case study from the 2003 fires in Victoria. Aust. For. 79, 1-14 (2016).

108. Scheiter, S., Higgins, S. I., Beringer, J. \& Hutley, L. B. Climate change and long-term fire management impacts on Australian savannas. N. Phytolog. 205, 1211-1226 (2015).

109. Beringer, J. et al. Fire in Australian savannas: from leaf to landscape. Glob. Chang. Biol. 21, 62-81 (2015).

110. Verhoeven, E. M., Murray, B. R., Dickman, C. R., Wardle, G. M. \& Greenville, A. C. Fire and rain are one: extreme rainfall events predict wildfire extent in an arid grassland. Int. J. Wildland Fire 29, 702-711 (2020).

111. Fairman, T. A., Nitschke, C. R. \& Bennett, L. T. Too much, too soon? A review of the effects of increasing wildfire frequency on tree mortality and regeneration in temperate eucalypt forests. Int. J. Wildland Fire 25, 831-848 (2016).

112. Cattau, M. E., Wessman, C., Mahood, A. \& Balch, J. K. Anthropogenic and lightning-started fires are becoming larger and more frequent over a longer season length in the U.S.A. Glob. Ecol. Biogeogr. 29, 668-681 (2020).

113. Coogan, S. C. P., Cai, X., Jain, P. \& Flannigan, M. D. Seasonality and trends in human- and lightning-caused wildfires $\geq 2$ ha in Canada, 1959-2018. Int. J. Wildland Fire 29, 473-485 (2020).

114. Binskin, M., Bennett, A. \& Macintosh, A. Royal Commission into National Natural Disaster Arrangements Report. 594pp. (Commonwealth of Australia, 2020). Detailed investigation initiated following the 2019-20 mega fires, with recommendations for improved disaster risk management in Australia.

115. Clarke, H. et al. Climate change effects on the frequency, seasonality and interannual variability of suitable prescribed burning weather conditions in south-eastern Australia. Agric. For. Meteorol. 271, 148-157 (2019).

116. Di Virgilio, G. et al. Climate change significantly alters future wildfire mitigation opportunities in southeastern Australia. Geophys. Res. Lett. 47, e2020GL088893 (2020).

117. Boer, M. M. et al. Changing weather extremes call for early warning of potential for catastrophic fire. Earth's Fut. 5, 1196-1202 (2017).

118. Bowman, D. M. J. S. et al. Human exposure and sensitivity to globally extreme wildfire events. Nat. Ecol. Evol. 1, 0058 (2017).

119. Price, O. F., Penman, T. D., Bradstock, R. A., Boer, M. M. \& Clarke, H. Biogeographical variation in the potential effectiveness of prescribed fire in south-eastern Australia. J. Biogeogr. 42, 2234-2245 (2015).

120. Trewin, B. et al. An updated long-term homogenized daily temperature data set for Australia. Geosci. Data J. 00, 1-21 (2020).

121. Jones, D. A., Wang, W. \& Fawcett, R. High-quality spatial climate data-sets for Australia. Aust. Meteorol. Oceanogr. J. 58, 233-248 (2009).

122. Huang, B. et al. Extended reconstructed sea surface temperature, version 5 (ERSSTv5): upgrades, validations, and intercomparisons. J. Clim. 30, 8179-8205 (2017).

123. Chan, D., Kent, E. C., Berry, D. I. \& Huybers, P. Correcting datasets leads to more homogeneous early-twentieth-century sea surface warming. Nature 571, 393-397 (2019).
124. Marshall, G. J. Trends in the Southern annular mode from observations and reanalyses. J. Clim. 16, 4134-4143 (2003).

125. Wooster, M. J., Roberts, G., Perry, G. L. W. \& Kaufman, Y. J. Retrieval of biomass combustion rates and totals from fire radiative power observations: FRP derivation and calibration relationships between biomass consumption and fire radiative energy release. J. Geophys. Res.: Atmos. 110, https://doi.org/ 10.1029/2005JD006318 (2005).

126. Giglio, L., Schroeder, W. \& Justice, C. O. The collection 6 MODIS active fire detection algorithm and fire products. Remot. Sens. Environ. 178, 31-41 (2016).

127. Resco de Dios, V. et al. A semi-mechanistic model for predicting the moisture content of fine litter. Agric. For. Meteorol. 203, 64-73 (2015).

128. Nolan, R. H. et al. Predicting dead fine fuel moisture at regional scales using vapour pressure deficit from MODIS and gridded weather data. Remot. Sens. Environ. 174, 100-108 (2016).

129. Sharples, J. J. \& McRae, R. H. D. Evaluation of a very simple model for predicting the moisture content of eucalypt litter. Int. J. Wildland Fire 20, 1000-1005 (2011).

130. Sharples, J. J., McRae, R. H. D., Weber, R. O. \& Gill, A. M. A simple index for assessing fuel moisture content. Environ. Model. Softw. 24, 637-646 (2009).

131. McArthur, A. G. Fire behaviour in Eucalyptus Forests. (Department of National Development Forestry and Timber Bureau, Canberra, 1967).

132. van Wagner, C. E. Development and Structure of the Canadian Forest Fire Weather Index System. Vol. 37 (Canadian Forestry Service, Ottawa, 1987).

133. Matthews, S. A comparison of fire danger rating systems for use in forests. Aust. Meteorol. Oceanogr. J. 58, 41-48 (2009).

134. Dowdy, A. J., Mills, G. A., Finkele, K. \& de Groot, W. Index sensitivity analysis applied to the Canadian Forest Fire Weather Index and the McArthur Forest Fire Danger Index. Meteorol. Appl. 17, 298-312 (2010).

135. Bradshaw, L.S., Demming, J. E., Burgan, R. E. \& Cohen, J. D. The 1978 National Fire-Danger Rating System: technical documentation. General Technical Report INT-169. Ogden, UT: U.S. Department of Agriculture, Forest Service, Intermountain Forest and Range Experiment Station. $44 \mathrm{p}$. (1984).

136. Mills, G. A. \& McCaw, L. Atmospheric stability environments and fire weather in Australia-extending the Haines Index. Vol. 151 (CSIRO and BOM, 2010).

137. Sharples, J. J., McRae, R. H. D., Weber, R. O. \& Gill, A. M. A simple index for assessing fire danger rating. Environ. Model. Softw. 24, 764-774 (2009).

138. Blanchi, R., Lucas, C., Leonard, J. \& Finkele, K. Meteorological conditions and wildfire-related houseloss in Australia. Int. J. Wildland Fire 19, 914-926 (2010).

139. Harris, S., Anderson, W., Kilinc, M. \& Fogarty, L. The relationship between fire behaviour measures and community loss: an exploratory analysis for developing a bushfire severity scale. Nat. Hazards 63, 391-415 (2012).

140. Blanchi, R. et al. Environmental circumstances surrounding bushfire fatalities in Australia 1901-2011. Environ. Sci. Policy 37, 192-203 (2014).

141. Noble, I. R., Gill, A. M. \& Bary, G. A. V. McArthur's fire-danger meters expressed as equations. Aust. J. Ecol. 5, 201-203 (1980).

142. Hawkins, E. et al. Observed emergence of the climate change signal: from the familiar to the unknown. Geophys. Res. Lett. 47, e2019GL086259 (2020).

143. Nolan, R. H., Boer, M. M., Resco de Dios, V., Caccamo, G. \& Bradstock, R. A. Large-scale, dynamic transformations in fuel moisture drive wildfire activity across southeastern Australia. Geophys. Res. Lett. 43, 4229-4238 (2016). Demonstrates that fire activity in forests and woodlands of southeast Australia, as quantified by burned area, strongly responds to fuel moisture thresholds.

144. Ruthrof, K. X. et al. How drought-induced forest die-off alters microclimate and increases fuel loadings and fire potentials. Int. J. Wildland Fire 25, 819-830 (2016).

145. Collins, L., Bennett, A. F., Leonard, S. W. J. \& Penman, T. D. Wildfire refugia in forests: Severe fire weather and drought mute the influence of topography and fuel age. Glob. Chang. Biol. 25, 3829-3843 (2019).

146. Penman, T. D., Bradstock, R. A. \& Price, O. Modelling the determinants of ignition in the Sydney Basin, Australia: implications for future management. Int. J. Wildland Fire 22, 469-478 (2013).

147. Dowdy, A. J. \& Mills, G. A. Atmospheric and fuel moisture characteristics associated with lightning-attributed fires. J. Appl. Meteorol. Climatol. 51, 2025-2037 (2012)

148. Parliament of Australia. 2019-20 Australian bushfires-frequently asked questions: a quick guide. Vol. 10 (Parliamentary Library, 2020).

149. Head, L. Transformative change requires resisting a new normal. Nat. Clim. Chang. 10, 173-174 (2020).

150. Graham, T. \& Keller, T. R. Bushfires, bots and arson claims: Australia flung in the global disinformation spotlight. Conversation (2020). https:// theconversation.com/bushfires-bots-and-arson-claims-australia-flung-in-theglobal-disinformation-spotlight-129556. 
151. Penman, T. D. et al. Examining the relative effects of fire weather, suppression and fuel treatment on fire behaviour-A simulation study. J. Environ. Manag. 131, 325-333 (2013)

152. Ndalila, M. N., Williamson, G. J., Fox-Hughes, P., Sharples, J. J. \& Bowman, D. M. J. S. Evolution of a pyrocumulonimbus event associated with an extreme wildfire in Tasmania, Australia. Nat. Hazard. Earth Syst. Sci. 20, 1497-1511 (2020).

153. McRae, R. H. D. \& Sharples, J. J. Forecasting conditions conducive to blow-up fire events. CAWCR Res. Lett. 11, 14-19 (2014).

\section{Acknowledgements}

We thank the Australian Research Council for funding support through the Centre of Excellence for Climate Extremes (CE170100023), a Future Fellowship to N.J.A. (FT160100029), and Discovery Indigenous grants to J.J.S. (IN140100011, IN160100029). We also thank the Australian Research Council and partner organisations for Linkage Project support to B.J.H. (LP150100062), the NSW Bushfire Risk Management Research Hub for support to M.M.B., R.H.N. and H.C., the Earth Systems and Climate Change (ESCC) Hub of the National Environmental Science Programme (NESP) for support to A.J.D, and the Bushfire and Natural Hazards Cooperative Research Centre for support to J.J.S. We thank Robert Whelan and Richard Williams (NSW Bushfire Risk Management Research Hub), Lynetter Bettio, Acacia Pepler and Robert Colman (Bureau of Meteorology), and Anthony Clark and Jason Crean (NSW Department of Primary Industries) for their reviews of this manuscript prior to submission.

\section{Author contributions}

N.J.A. and T.J.R.L. proposed this review and assembled the research team, and all authors contributed to discussions of the manuscript scope and design. N.J.A., B.J.H., A.S.G. and T.J.R.L. produced the figures with data assembled and analysed by N.J.A., B.J.H., A.J.D., J.J.S., R.H.N., T.Z., M.J.W. and B.P.M. The text was written by N.J.A. with assistance and review from B.J.H., A.S.G., T.J.R.L., H.C., A.J.D., J.J.S., R.H.N., M.J.W. J.B.W., K.J.M., A.J.P., A.M.U., B.P.M., N.J.T. and M.M.B.

\section{Competing interests}

The authors declare no competing interests.

\section{Additional information}

Supplementary information is available for this paper at https://doi.org/10.1038/s43247020-00065-8.

Correspondence and requests for materials should be addressed to N.J.A.

Peer review information Primary handling editor: Heike Langenberg.

Reprints and permission information is available at http://www.nature.com/reprints

Publisher's note Springer Nature remains neutral with regard to jurisdictional claims in published maps and institutional affiliations.

Open Access This article is licensed under a Creative Commons Attribution 4.0 International License, which permits use, sharing, adaptation, distribution and reproduction in any medium or format, as long as you give appropriate credit to the original author(s) and the source, provide a link to the Creative Commons license, and indicate if changes were made. The images or other third party material in this article are included in the article's Creative Commons license, unless indicated otherwise in a credit line to the material. If material is not included in the article's Creative Commons license and your intended use is not permitted by statutory regulation or exceeds the permitted use, you will need to obtain permission directly from the copyright holder. To view a copy of this license, visit http://creativecommons.org/ licenses/by/4.0/.

(C) The Author(s) 2021

Nerilie J. Abram (10 ${ }^{1,2}$, Benjamin J. Henley (10 ${ }^{3,4,5}$, Alex Sen Gupta (1) 6,7, Tanya J. R. Lippmann ${ }^{8}$, Hamish Clarke 9,10,11, Andrew J. Dowdy ${ }^{12}$, Jason J. Sharples ${ }^{13,14}$, Rachael H. Nolan ${ }^{10,11}$, Tianran Zhang ${ }^{15}$, Martin J. Wooster ${ }^{15}$, Jennifer B. Wurtzel ${ }^{16}$, Katrin J. Meissner (10) 6,7, Andrew J. Pitman ${ }^{6,7}$, Anna M. Ukkola (1) ${ }^{1,2}$, Brett P. Murphy ${ }^{17}$, Nigel J. Tapper ${ }^{3}$ \& Matthias M. Boer (10 ${ }^{10,11}$

${ }^{1}$ Research School of Earth Sciences, Australian National University, Canberra, ACT 2601, Australia. ${ }^{2}$ ARC Centre of Excellence for Climate Extremes, Australian National University, Canberra, ACT 2601, Australia. ${ }^{3}$ School of Earth, Atmosphere and Environment, Monash University, Melbourne, VIC 3800, Australia. ${ }^{4}$ School of Earth Sciences, University of Melbourne, Melbourne, VIC 3010, Australia. ${ }^{5}$ ARC Centre of Excellence for Climate Extremes, Monash University, Melbourne, VIC 3800, Australia. ${ }^{6}$ Climate Change Research Centre, University of New South Wales, Sydney, NSW 2052, Australia. ${ }^{7}$ ARC Centre of Excellence for Climate Extremes, University of New South Wales, Sydney, NSW 2052 , Australia. ${ }^{8}$ Department of Earth Sciences, Vrije Universiteit Amsterdam, $1081 \mathrm{HV}$ Amsterdam, The Netherlands. ${ }^{9}$ Centre for Environmental Risk Management of Bushfires, University of Wollongong, Wollongong, NSW 2522, Australia. ${ }^{10}$ Hawkesbury Institute for the Environment, Western Sydney University, Penrith, NSW 2751, Australia. ${ }^{11}$ NSW Bushfire Risk Management Research Hub, Wollongong, NSW 2522, Australia. ${ }^{12}$ Climate Research Section, Bureau of Meteorology, Melbourne, VIC 3000, Australia. ${ }^{13}$ School of Science, University of New South Wales, Canberra, ACT 2600, Australia. ${ }^{14}$ Bushfire and Natural Hazards Cooperative Research Centre, Melbourne, VIC 3002, Australia. ${ }^{15}$ NERC National Center for Earth Observation/Leverhulme Center for Wildfires, Environment and Society, Department of Geography, King's College London, London WC2B 4BG, UK. ${ }^{16}$ NSW Department of Primary Industries, Orange Agricultural Institute, Orange, NSW 2800, Australia. ${ }^{17}$ NESP Threatened Species Recovery

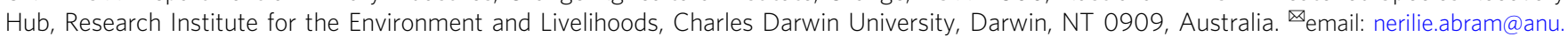
edu.au 